\title{
EREBEA
}

Revista de Humanidades

y Ciencias Sociales

Núm. 4 (2014), pp. 225-259

ISSN: 0214-0691

\section{UN GIGANTE CON LOS PIES DE BARRO: LA TORRE DEL RÍO DEL ORO EN EL SIGLO XVIII}

\author{
Juan Villegas Martín \\ Antonio Mira Toscano \\ Universidad de Huelva
}

RESUMEN

Tal vez por las preguntas que nos hacemos ante sus carcomidos restos, la torre del Río del Oro ocupa un lugar destacado entre las atalayas destruidas de la costa de Huelva. Sin embargo, más allá de su referencia en trabajos generales sobre el sistema de almenaras, se trata de una torre muy desconocida, tanto en lo tocante a su historia como a su morfología, características y estado de defensa. El presente trabajo pretende, por medio de un acercamiento documental y cartográfico, avanzar en el conocimiento de tan interesante edificio, explicando su papel como elemento defensivo primordial de un enclave estratégico y analizando las reformas que sufrió durante el siglo XVIII para atender a la problemática de cimentación que finalmente acabaría por destruirla.

Palabras Clave

Torres de almenara, defensa costera, fortificaciones, ingenieros militares, costa de Andalucía.

Fecha de recepción: 22 de abril de 2014

Fecha de aceptación: 23 de octubre de 2014

\section{Abstract}

Maybe because of the questions that we ask ourselves when we are in front of its eaten-away remains, the tower of Río del Oro takes a prominent position among the ruined watch towers on the coast of Huelva. Nevertheless, apart from its mention in general studies on the system of beacon towers, it is a very unknown one, not only if we refer to its history and morphology, but also to its characteristics and condition of defence. The present study expects, by means of a documentary and cartographic approach, to progress in the knowledge of such an interesting construction, explaining its role as a defensive basic element of a strategic spot and analyzing the reforms that suffered in order to help its foundation problems during the 18th century, a circumstance which finally destroyed it.

KEYWORDS

Watch towers, coastal defence, fortifications, military engineers, Andalusian coast. 



\section{INTRODUCCIÓN Y CONTEXTO HISTÓRICO}

Pasadas las turbulencias generadas por la Guerra de Sucesión, el siglo XVIII español va a suponer la introducción en el país de una serie de cambios ideológicos y políticos orientados a su gradual transformación y modernización. Con la instalación de la dinastía borbónica, procedente de la racionalista Francia, se vivirá un tiempo de reformas y proyectos, marcado por el deseo de remodelar la administración, de mejorar las fuentes de riqueza y de racionalizar la actividad pública. Imprescindible será el papel, ya desde el reinado de Felipe V, de una serie de ministros cuya elección queda como uno de los mayores aciertos de la nueva dinastía, colaboradores políticos que habrían de destacar por el sentido común y el impulso del proceso reformista ${ }^{1}$.

En el campo de la política exterior, tras una fase de proyección hacia Europa y de búsqueda del equilibrio de las potencias en el viejo continente, la mirada de España va a centrase en el frente atlántico. Conscientes de que el futuro y la prosperidad del país dependían más que nada del comercio ultramarino, y de que era en este escenario donde se jugaría la partida del equilibrio de poderes, los ministros de Fernando VI orientaron hacia América sus propósitos, aunque esto supusiera la hostilidad de Inglaterra. A pesar de ello y de algunos episodios bélicos de corto alcance, España vivió con el sucesor de Felipe $\mathrm{V}$ uno de los escasos períodos de su historia exentos de enfrentamientos armados, aunque la política no siguiera criterios estrictamente pacifistas, sino más bien los de una cierta "neutralidad armada"

Así, con la calma de la ausencia de guerras y el dinero economizado en consecuencia, la administración de Fernando VI desarrolló un importante programa de mantenimiento y restauración de las instalaciones militares existentes, mejorando la capacidad defensiva del país ${ }^{3}$. Habrían de jugar en ello un papel determinante políticos de la talla del marqués de la Ensenada, ministro de la Guerra y la Marina, a quien se debe una importante reorganización de ejército

1 José Luis Comellas García-Llera, Historia de España moderna y contemporánea. Madrid: Rialp, 1971, pp. 191-194.

2 José María Oliva Melgar, "Política exterior en el siglo XVIII”, en Antonio Domínguez Ortiz (dir.): Historia de España. Barcelona: Planeta, 1989, pp. 321-434.

3 Antonio GIL ALBARRACIN, Documentos sobre la defensa de la costa del reino de Granada (1497-1857). Barcelona: Ingoprint S.A., 2004, pp. 52-53. 
y armada. También serían esenciales unos profesionales altamente capacitados, los ingenieros militares, formados ahora bajo criterios técnicos, racionalistas e ilustrados. La creación de este cuerpo a principios del siglo XVIII responde con claridad a las ideas borbónicas de centralización monárquica y control del territorio ${ }^{4}$. Con un funcionamiento organizado y jerárquico, ellos se ocuparán a lo largo del siglo de los múltiples proyectos destinados a la puesta en estado de defensa de las fortificaciones españolas.

En este contexto, la costa onubense se nos presenta como un espacio deficientemente fortificado, donde funciona el sistema defensivo puesto en marcha a principios del siglo XVII, a pesar de su progresivo deterioro y, en algunos casos, abandono. Las torres de almenara son aún, a pesar de todo, un medio imprescindible para vigilar y defender este litoral, pues a viejos peligros como la piratería norteafricana se pueden unir otros derivados de la nueva situación geopolítica de España. Por ello, sobre todo en el tercio central del siglo, asistiremos a una importante preocupación por el estado y la reparación de las defensas, que cristalizará en ocasiones en importantes proyectos y obras destinadas a su rehabilitación ${ }^{5}$.

Precisamente uno de los ingenieros militares, Ignacio de Sala, reflejará en una visita efectuada en 1739 al litoral onubense ${ }^{6}$ lo desprotegido de las villas, lugares abiertos y con sus viejos castillos arruinados, y el escaso amparo que ofrecen las torres costeras. "Repartidas de manera y con tales distancias que de la una a la otra se pueden hacer las señales", el ingeniero indica la necesidad de su reparación en muchos casos, reponiendo en la mayor parte, y es solo un ejemplo, el revoco arrancado de los muros por las aguas y los temporales. En otros casos refleja incluso la inutilidad, en el estado en que se hallan, de varias de estas torres, como las de Zalabar, La Higuera o El Asperillo. Todo ello sin contar, pues parece desconocerlo, con la ya antigua desaparición de al menos dos de las almenaras inicialmente construidas en este sector costero 7 .

4 Martine Galland-Seguela, "Los ingenieros militares españoles en el siglo XVIII", en Alicia Cámara Muñoz (coord.): Los ingenieros militares de la monarquía hispánica en los siglos XVII y XVIII. Madrid: Fernando de Villaverde Ediciones, 2005, pp. 205-231.

5 Tal preocupación llevó incluso a la reedificación de alguna torre completa, como la del Asperillo.

6 A(rchivo) C(artográfico) y de E(studios) G(eográficos) del Centro Geográfico del Ejército, C-58, $\mathrm{n}^{\circ}$ 1. Relación remitida por el ingeniero Ignacio Salas (sic) de la costa y frontera de Andalucía en 1739 .

7 Las de Morla y Marijata. Sobre estas torres desaparecidas véase Antonio Mira Toscano, Juan Villegas Martín y Juan Luis Carriazo Rubio, "Una almenara perdida en la costa de Palos: la torre de Morla”, Archivo Hispalense, no 279-281, tomo XCII (2009), pp. 107-125. Y Juan Villegas Martín y Antonio Mira Toscano, "Torres de almenara y defensa de la costa en el Marquesado de Gibraleón", en Juan Luis Carriazo Rubio (ed.): Fortificaciones, guerra y frontera en el Marquesado de Gibraleón. Huelva: Diputación Provincial, 2012, pp. 189-231. 
También una de las torres más importantes de la costa onubense, la del Río del Oro, se encontraba afectada por el deterioro que desgastaba paulatinamente al sistema. A lo largo del siglo XVIII veremos crecer la preocupación por su estado, imponiéndose finalmente la realización de costosas obras de reforma y consolidación en la atalaya. Las fuentes documentales que manejamos nos han permitido no solo acercarnos a este interesante proceso, plenamente inserto en las coordenadas políticas de su tiempo, sino que también nos han revelado importantes datos sobre la desconocida morfología de esta almenara.

\section{UNA TORRE ACTIVA EN UN ENCLAVE ESTRATÉGICO}

La consulta de la documentación generada en el transcurso del largo proceso de construcción de las torres de almenara de la costa de Huelva permite apreciar que la torre del Río del Oro, también llamada simplemente del Oro, era una de las almenaras más fuertes del litoral onubense. La atalaya, que compartía esta condición con las de San Jacinto, Punta Umbría y Canela, se levantaba exactamente en la frontera de los dominios señoriales del duque de Medina Sidonia, señor de Almonte, con los del conde de Miranda, señor de Palos ${ }^{8}$, y era la única de grandes dimensiones que no protegía desembocaduras o estuarios de ríos. Esta excepcionalidad tenía sin duda una justificación: la defensa de un lugar estratégico de gran importancia, como era el paraje del Río del Oro. Allí, desde tiempo inmemorial faenaban y vivían numerosas personas ocupadas en la pesca ${ }^{9}$, dándose además la circunstancia, complementaria de la anterior, de que el lugar proporcionaba abundante agua potable y era por ello punto vital de abastecimiento para los navegantes, tanto amigos como enemigos ${ }^{10}$. Una cosa y la otra lo convertían en un punto de especial atracción para la piratería berberisca, de manera que en los proyectos constructivos iniciales siempre aparece la necesidad de que la torre ubicada en la zona llevara artillería y, por lo tanto, gozara de la consistencia necesaria para montarla.

8 En la actualidad se encuentra en la confluencia de los términos de Almonte, Lucena del Puerto, Palos de la Frontera y Moguer.

9 Sobre la importancia de este asentamiento en los siglos XV y XVI, véase Domingo Muñoz BORT, "El ingeniero Luis de Montalbán y la fortificación de la costa atlántica de Andalucía en el siglo XVI”, Erebea, no 3 (2013), pp. 293-327. En el siglo XVIII, el Río del Oro llegó a ser uno de los enclaves pesqueros más importantes de la costa oriental onubense. Francisco García García, "Pesca y almadrabas en la costa de Dońana”, en David González Cruz (coord.): La pesca en el golfo de Cádiz: el aprovechamiento de los recursos marinos en la costa onubense (siglos $X V-X X$ ). Sevilla: Consejería de Agricultura y Pesca de la Junta de Andalucía, 2009, pp. 123-144.

10 A(rchivo) G(eneral) de S(imancas), Guerra Antigua, leg. 155/10. Relación de las torres que paresçe aver menester en la costa desde Sant Lucar hasta el cabo de Santa María que es a poniente de Faro. Sin fecha, aunque esta debe estimarse en torno a 1583. Véase Luis de Mora-Figueroa Dingwall-Williams, Torres de almenara de la costa de Huelva. Huelva: Diputación Provincial, 1981. Reedición en 2003, p. 89. 
De la magnitud y fortaleza de la torre nos daban noticia ya las relaciones coetáneas de la época de su construcción, como la enviada por el Consejo de Guerra a Felipe III en julio de 1608, donde se manifiesta que "es la más importante del término del Monte"11, o la firmada por el Capitán Mexía Bocanegra en 1618, que la considera "muy buena [torre]"12. Sin embargo, el punto débil de la construcción no se encontraba en su tamaño, sino en su ubicación. Construida sobre las arenas, al pie de un arroyo -el llamado "Río del Oro"- cuyo curso acariciaba su base, y expuesta directamente a los embates del mar, la poderosa almenara era potencialmente un gigante con los pies de barro. No obstante, la preocupación por la estabilidad de la fábrica no se dejaría sentir seriamente hasta mucho después. No hay motivos para dudar de la consistencia de la torre al menos durante el primer siglo y medio de su existencia; otra cosa será después.

Es la antes citada relación del ingeniero Ignacio de Sala ${ }^{13}$ la que, en 1739, nos da cuenta ya de algunos leves desperfectos en la fábrica y nos hace concebir la idea de que la atalaya empezaba a atravesar ciertas dificultades. Así, el ingeniero consideraba preciso "redificar (sic) su remate o esplanada para que las aguas no acaben de destruir sus bóvedas", así como llevar a cabo "un buen reparo en su caracol con otras pequeñas obras de poco valor" ${ }^{\prime 4}$. Nada, aparentemente, que no pudiera ser solventado con unas más o menos ligeras reparaciones, $y$, desde luego, nada relacionado en principio con la cimentación o la solidez del edificio. El documento nos presenta una torre en estado de actividad, en consonancia con el resto del sistema de almenaras, que aún resultaba plenamente necesario para la seguridad del litoral. Sin embargo esta actividad no puede ser considerada completa, ya que su artillería, "dos cañones de hierro de a 8 [se encuentran] desmontados" 15 , por lo que solo parece desarrollar en la fecha labores de vigilancia y aviso a cargo de los tres torreros de que dispone. La peligrosidad del paraje,

11 A.G.S., Guerra Antigua, leg. 689. Véase Mora-Figueroa, Torres de almenara ..., p. 112.

12 A.G.S., Guerra Antigua, Sección Guerra y Marina, leg. 819. Relación del capitán Mexía Bocanegra, con la relaçión inclusa del estado que tienen las torres de la costa de Andaluçía y lo que será menester para su defensa. Véase Juan Villegas Martín, Antonio Mira Toscano y Juan Luis Carriazo Rubio, "Nuevas aportaciones para la historia de las torres de almenara onubenses", Huelva en su Historia, $\mathrm{n}^{\circ} 12$ (2005), pp. 99-130.

13 Conocido por su participación en emblemáticos proyectos como el de la nueva Fábrica de Tabacos de Sevilla, Ignacio Sala Garrigo destacó por su trabajo como ingeniero militar en Andalucía. En 1740 fue nombrado mariscal de campo e ingeniero director de las fortificaciones de Cádiz, provincia donde colaboró con otros conocidos ingenieros como Joseph Barnola. En el territorio onubense, además de su intervención en las fortificaciones litorales, trazó planos de los castillos de Sanlúcar de Guadiana y Ayamonte. Extremadura o América son otros ámbitos geográficos donde desarrolló su actividad profesional. María Gloria Cano Révora, Cádiz y el Real Cuerpo de Ingenieros Militares (1697-1847). Cádiz: Universidad de Cádiz, 1994, pp. 371-386.

14 A.C.E.G., C-58, no 1 . Relación remitida por el ingeniero Ignacio Salas...1739.

15 Ibidem. El uso del hierro en los cañones estaba generalizado en la artillería del siglo XVIII, especialmente en la Marina. 
"donde los moros vienen mui a menudo [a] hacer aguada" atraídos por el "riachuelo de agua mui buena para bever" que corre al pie de la torre y por las "bastantes fuentes" existentes en sus cercanías, hace que Ignacio de Sala aconseje la rehabilitación de uno de los cañones y traer dos más desde la torre de San Jacinto $^{16}$. A decir verdad, resulta extraño el abandono en que se encontraba la artillería de la torre, lo que debió de convertirla mientras duró esta situación en un objetivo al alcance de la mano para la constante piratería norteafricana.

En cualquier caso, durante su visita en 1739 a la atalaya el ingeniero pudo contemplar una potente torre "de figura cilíndrica, como las antecedentes", de una altura de "ocho tuesas y media, y seis de diámetro en su vasa" ${ }^{17}$. La entrada, que se encontraba "a la altura de tres tuesas", era accesible por medio de una escalera de madera, pareciéndole la torre maciza hasta la altura de la puerta ${ }^{18}$.

Complementaria a esta información resulta la planimetría que publicamos en este artículo, fechada solo unos ańos después. Hablaremos en primer lugar de un plano de 1742, el Plano de la barraca que se construyó ymmediato a la torre y Río del Oro... ${ }^{19}$, que nos presenta una imagen demasiado sumaria de la torre, pero nos permite conocer con detalle su ubicación y alrededores. Este documento nos muestra primeramente el profundo barranco excavado por el Río del Oro sobre la terraza litoral, poco antes de su desembocadura al pie de la atalaya. Junto a este arroyo se señala un camino principal que iba a la villa de Almonte y otras dos veredas, una a cada lado de la garganta. Resulta interesante la existencia, sobre el cauce de este arroyo y a pocos metros de la almenara, de un molino fluvial, que ya en la fecha se encontraba arruinado ${ }^{20}$. Podemos clasificar dicho ingenio entre los llamados "molinos de cubo", tipología en uso al menos en el siglo XVI concebida para aprovechar pequeños cauces como el que nos ocupa, y en los que el agua era recogida lentamente en un depósito en forma de columna para posteriormente ser vertida de golpe y con ello accionar la maquinaria de molienda localizada en la construcción contigua ${ }^{21}$. La existencia de este molino supone una nueva

16 Ibidem.

17 La "tuesa" o toesa es una medida de origen francés, muy usual en Espańa a partir de 1700. Su equivalencia se estima en 1,949 metros. Guillermo Duclós Bautista, La fortificación de un territorio. Arquitectura militar en la raya de Huelva, siglos XVII y XVIII. Huelva: Diputación Provincial, 2002, p. 258.

18 A.C.E.G., C-58, no 1 . Relación remitida por el ingeniero Ignacio Salas...1739. A pesar de esta observación de Sala, la torre del Oro no era maciza. Véase el apartado 4 de este artículo.

19 A.G.S., Mapas, Planos y Dibujos, 56, 031. Plano de la barraca que se construyó ymmediato a la torre y Río del Oro de orden del Excelentísimo Señor el conde le Roy le ville. Año de 1742. Véase figura 1.

20 El trabajo antes citado de Muńoz Bort, “El ingeniero Luis de Montalbán...”, pp. 302-303, hace mención de varios molinos en este paraje entre finales de la Edad Media y la Edad Moderna.

21 Los molinos de cubo son comunes en la sierra de Huelva y sur de Extremadura. Véase María López Romero, "Conjunto de molinos de cubo en Fregenal de la Sierra", en S. Huerta, I. Gil, S. 
actividad humana complementaria de las que hemos señalado anteriormente para este paraje, subrayando con ello su carácter de punto estratégico necesitado de defensa.

Del mismo modo que en el informe de Sala, la torre del Río del Oro aparece representada en este plano como una gruesa almenara, que se conserva en la fecha completa y aparentemente activa. Un corte en planta a la altura de la puerta, orientada hacia el Norte, muestra la escalera de caracol y el espacio interior de una de las cámaras. Poco más puede deducirse de la escueta representación, ya que la almenara no es el objeto principal del plano. Situada sobre la playa, la torre del Río del Oro queda en claro contacto con las aguas marinas, aunque no se especifican las indudables diferencias de nivel entre mareas altas o bajas. Sí se representa con claridad la corriente de agua constante que supone el arroyo del Oro, cuya desembocadura queda dibujada justo al pie de la torre, al oeste de la misma.

No podemos albergar dudas sobre el mantenimiento en estas fechas del valor estratégico del enclave y de la propia torre. La prueba patente de ello es la construcción, muy cerca de la atalaya, de un nuevo establecimiento militar. Se trata de un barracón, ubicado en la orilla izquierda del Río del Oro y sobre una explanada de aproximadamente unos 375 metros cuadrados excavada en forma de terraza en la parte alta del talud ${ }^{22}$. Según la leyenda del plano, la instalación había sido ordenada por el "conde le Roy le Ville (sic)", en realidad conde de Roydeville ${ }^{23}$, militar de origen flamenco que era en la fecha capitán general de la Costa de Andalucía y por ello responsable último de la defensa de este litoral. El destino de la barraca era albergar una partida de caballería de unos 20 caballos encargados de la vigilancia costera y del control sanitario del acceso a la zona. Era, según se aprecia por el plano, un edificio de carácter rústico y alargada planta rectangular ( 35 metros de largo por casi 4 de ancho), con tres fachadas cerradas y una, la principal, abierta. Tenía una estructura simple, basada en una doble alineación de 28 pilares redondos, tal vez simples troncos desnudos, que sostendrían una cubierta muy posiblemente a una sola agua y de material vegetal,

García, M. Taín (eds.): Actas del VII Congreso Nacional de Historia de la Construcción. Madrid: Instituto Juan de Herrera, 2011, pp. 767-776. Y José Antonio Muñiz Carrasco, "Tipología de molinos harineros en la Sierra", Ponencias y comunicaciones de las VI Jornadas del Patrimonio de la Sierra. Huelva: Diputación Provincial, 1996, pp. 93-115.

22 En la actualidad, no existen restos visibles de esta construcción, pero puede aún reconocerse lo que parece ser su huella en el talud. Véase figura no 2 .

23 Juan Fernando de Roydeville, conde de Roydeville, ocupó la Capitanía General de la Costa de Andalucía entre los años 1737 y 1749. María Luisa Álvarez Y Cañas, "Las conflictivas relaciones entre los corregidores militares y los capitanes generales de la Costa de Andalucía y de la Costa de Granada en el siglo XVIII", Baetica, no 33 (2011), pp. 253-281. Anteriormente había desempeñado otros cargos importantes, como los de gobernador de Barcelona o de Alicante y el de comandante general del Campo de Gibraltar. 

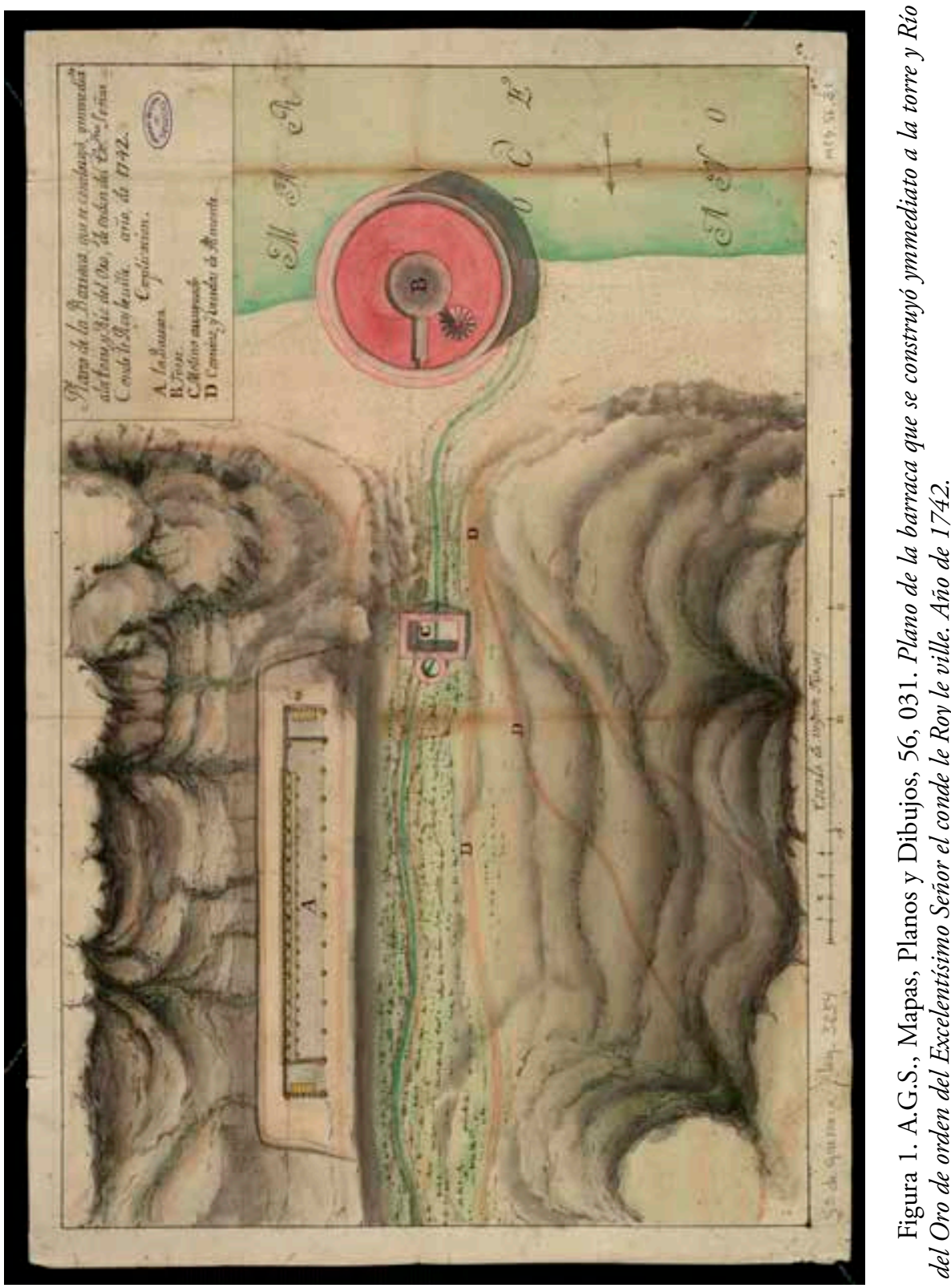


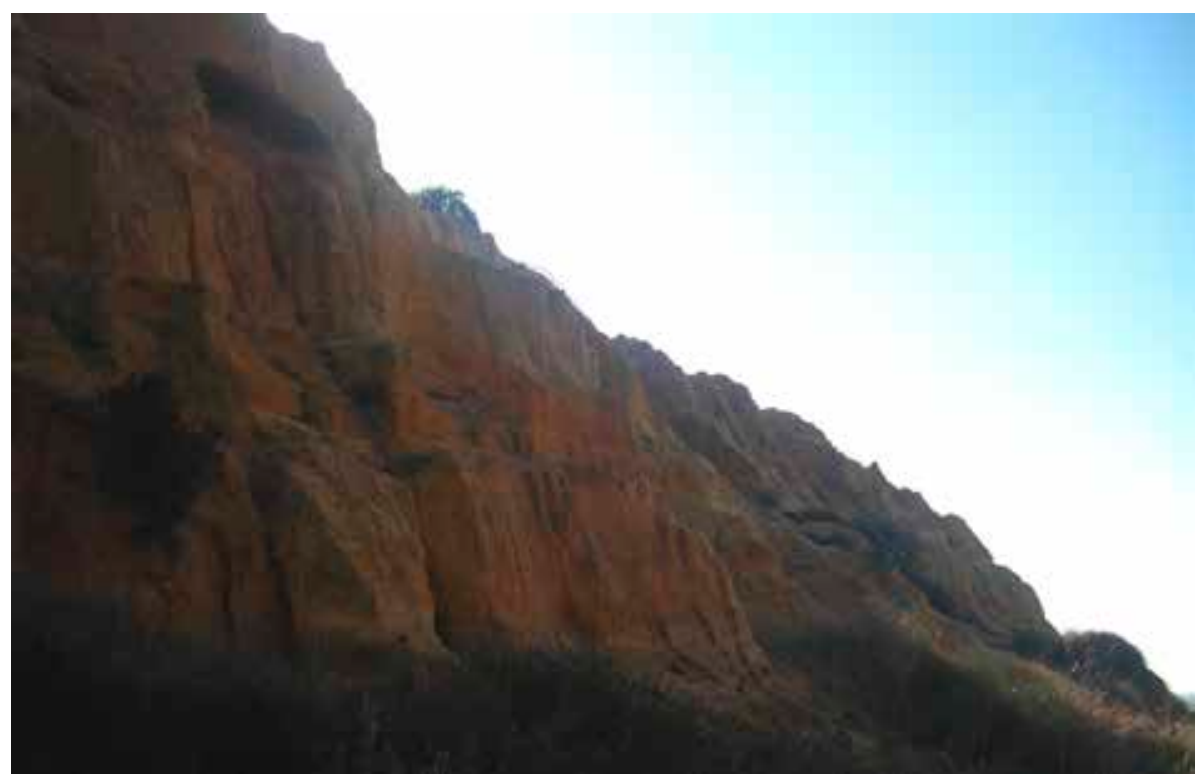

Figura 2. Ladera este del arroyo del Oro, en cuya falda puede apreciarse la probable ubicación del barracón construido antes de 1742 (fotografía de los autores).

a modo de choza. Por su planta sabemos que los 20 pesebres ocupaban gran parte de la superficie útil, disponiéndose en los extremos de la construcción sendos aposentos para la tropa.

La instalación del barracón del Río del Oro debe ponerse en relación con la serie de acuartelamientos de caballería proyectados en 1740 por el coronel e ingeniero director Gerónimo Amicy. Dentro de este plan, 19 cuarteles fueron diseñados en el territorio onubense, encuadrados en la política borbónica de organización y control del territorio ${ }^{24}$. Se trataba de un sistema defensivo basado en unidades militares de gran movilidad, como eran las compañías de caballería, concebidas para la vigilancia y defensa de la zona fronteriza hispanolusa, incluyendo el control del contrabando, sobre todo de café y sal. El proyecto de Amicy debía cerrar la frontera y la costa, estableciendo un lugar central Ayamonte- donde las compañías del Regimiento de Caballería provincial de Andalucía pudieran reunirse en el plazo máximo de 48 horas. Dado que la línea de cuarteles encargados de asegurar la costa tendría en Moguer su establecimiento más oriental, parece existir una insuficiente vigilancia del extenso litoral de las

24 Sobre el plan de acuartelamientos de 1740 véase Guillermo Duclós Bautista, La fortificación de un territorio..., pp. 235-250. Y Juan Carlos Hernández Núñez, "Gerónimo Amici y los proyectos de cuarteles para el regimiento de caballería de Andalucía, en la provincia de Huelva", Espacio, Tiempo y forma, Serie VII, Historia del Arte, t. 4, (1991), pp. 239-264. 
Arenas Gordas, tan alejado de las poblaciones, a pesar de que esta zona era una de las que más preocupaba en los informes preliminares del proyecto. En ellos se manifestaba que "en Arenas Gordas se debe poner todo cuidado, pues a (sic) sido y será el mare magnun (sic) de los desembarcos de los contravandos para Sevilla, su Ajarafe y su tierra adentro" ${ }^{25}$. Esto hace pensar que el barracón del Río del Oro, ya existente en 1742, pudo haber sido levantado para cubrir la necesidad de complementar a los acuartelamientos citados, formando parte tal vez de una red litoral de barracas o puntos de avituallamiento para el descanso de tropas y cabalgaduras. Desde ellos se patrullaría el solitario territorio costero hasta la punta de Malandar, junto a la desembocadura del Guadalquivir.

A pesar de la sencillez de la construcción, su capacidad para 20 caballos colocaba a esta simple barraca al mismo nivel que los cuarteles previstos en poblaciones costeras como Lepe, y por encima de los de otras como La Redondela o Cartaya, de solo 15 unidades. En cualquier caso, se trataba de un edificio de escasa consistencia, a causa de los materiales empleados, lo que queda de manifiesto por la necesidad de su arreglo ya en 1752. En dicho ańo se ordenaba, con cargo a las poblaciones comarcanas, la reparación del "barracón que está inmediato a la torre del Oro en esas costas", puesto que era preciso "establecer en él una partida de caballería que las patrulle, defienda del desembarco de los moros, y al mismo tiempo haga el resguardo de la peste que se padece en Argel"26.

La concentración de fuerza en el lugar indica que, como casi dos siglos antes, seguía siendo un punto muy activo de control y vigilancia. Además de la construcción del barracón, esta apuesta por el Río del Oro se concretaría, según creemos probable, en la atención a las sugerencias expresadas por Ignacio de Sala en 1739 para la reparación de la torre de almenara. Como se ha visto, el ingeniero había centrado su atención en el terrado y la escalera de caracol, además de en la artillería. Disponemos de un segundo plano, el titulado Plano y perfil de la torre del Rio del Oro que demuestra las dos brechas que tiene su fundamento a los frentes del Sur y del Poniente... ${ }^{27}$, cuya consulta resulta vital para entender la estructura y los problemas de la atalaya. Se trata de un documento de gran fiabilidad, como

25 A.G.S., Secretaría de Guerra, leg. 3.673. Citado por Francisco García García y Antonio Manuel González Díaz, "Los cuarteles de caballería en la comarca de la Sierra en el contexto del proyecto para la defensa de la frontera de la Monarquía Borbónica en el siglo XVIII", en Francisco del Valle y Natalia Santos (eds.): XXII Jornadas de Patrimonio de la comarca de la Sierra (Huelva), Huelva: Diputación Provincial, 2010, pp. 287-308.

26 A(rchivo) M(unicipal) de M(oguer), leg. 10. Citado por Diego Ropero-Regidor, "Defensa y resguardo de las playas de Castilla a mediados del siglo XVIII: el barracón de la torre del Oro", Mazagón en fiestas, (2004), pp. 65-67.

27 A.G.S., Mapas, Planos y Dibujos, 56, 030. Plano y perfil de la torre del Río del Oro que demuestra las dos brechas que tiene su fundamento a los frentes del Sur y del Poniente, muy difíciles de componer por no poderse llegar a descubrir el terreno sólido para cimentar estos reparos. En un expediente de la costa de Poniente. 1749. Véase figura 3. 
corresponde a la mayor parte de la planimetría dieciochesca, elaborado conforme a sistemas normalizados de representación y siguiendo pautas de indudable rigor y detalle. De su consulta podemos extraer numerosas conclusiones, pero nos ocuparemos primeramente de ciertas observaciones que nos hacen concebir la idea de que no mucho después de la visita de Sala se llevaron a cabo algunas obras. Centrado en la almenara, el plano nos ofrece un corte horizontal a la altura del terrado que muestra la existencia de una construcción ocupando la mitad del mismo. Se trata de una extraordinariamente desarrollada garita de salida de la escalera, poco común por su tamaño entre las almenaras onubenses ${ }^{28}$. Precisamente por ello nos parece difícil que tal construcción, que constituye casi una tercera cámara y reduce a la mitad la superficie del terrado, corresponda a la edificación original. Más bien creemos que pudiera ser una obra del siglo XVIII efectuada para responder conjuntamente a las necesidades expresadas por Sala, pues se trata de un arreglo de la explanada superior, cubre la escalera de caracol y deja espacio suficiente para albergar quizá la munición o los pertrechos de la artillería.

3. Preocupación por la estabilidad de la torre en los Comedios Del SIGLO XVIII

En cualquier caso, y a pesar de estas más que posibles reformas, hasta estas fechas no se detecta en la documentación una preocupación que pueda calificarse de seria por el estado de la torre del Río del Oro. Pero las cosas cambian notablemente a medida que nos acercamos a los comedios del siglo, cuando un conjunto de circunstancias viene a provocar deterioros que podrían incluso llegar a comprometer la solidez de la almenara. Así nos lo indican este segundo plano que acabamos de citar y su documentación adjunta, consistente en la correspondencia cruzada entre una serie de personajes que, en diversos grados jerárquicos, eran en el momento los responsables de la conservación y estado de defensa de la torre.

El primero de estos personajes es Pedro Mateos, quien, en su calidad de "requeridor de las torres de Poniente" es el responsable más directo de la almenara, por encima de los centinelas en ella emplazados ${ }^{29}$. Este cargo, que ya figura desde el siglo XVII en la nómina del personal vinculado a las atalayas ${ }^{30}$, tenía por misión controlar la seguridad de un sector costero, supervisando a los vigilantes y velando por el estado de los edificios. Mateos era ya citado por Ignacio de Sala en 1739 como responsable de las torres de la jurisdicción de Sanlúcar de Barrameda, demarcación en la que incluía las de San Jacinto, Zalabar, Carbonero, la Higuera,

28 En un plano firmado por José Huet en 1797 sobre la torre de San Jacinto se dibuja una garita similar, aunque más pequeña. Juan Luis Carriazo Rubio, José María Cuenca López y Nicola Palmieri, Huelva, tierra de castillos. Huelva: Diputación Provincial, 2004, p. 241.

29 A.G.S., Secretaría de Guerra, leg. 3.254. Cádiz, 26 de marzo de 1748.

30 Ibidem, Mar y Tierra, leg. 819. Relación de las torres que hay en la costa del mar de Andalucía desde la torre del Pinoseco de la Canela en la barra de Ayamonte hasta la torre de la Chullera. Año 1616. 


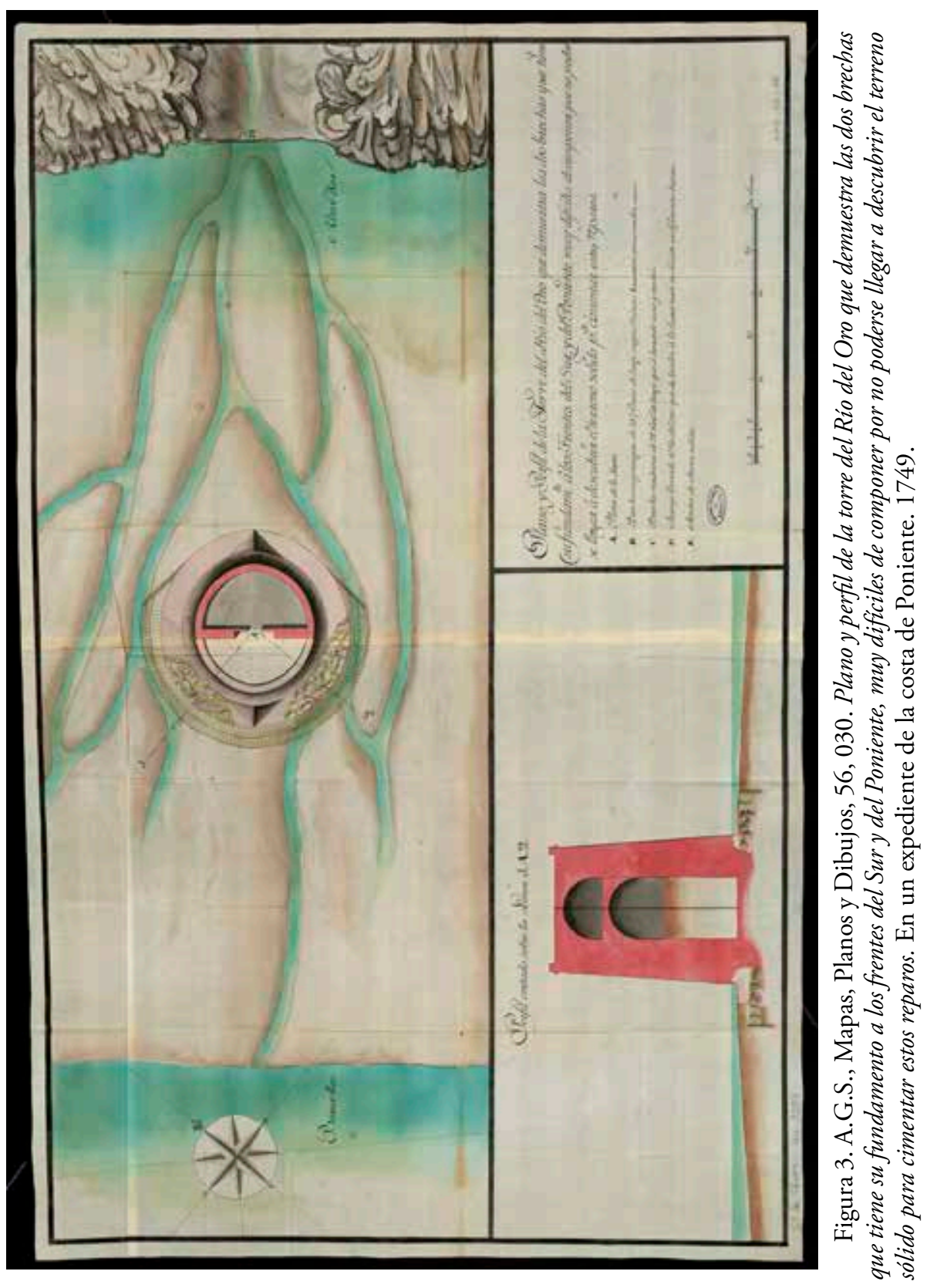


Asperillo y del Oro ${ }^{31}$. El cargo detentado por Pedro Mateos se recoge también en la documentación que manejamos bajo otras denominaciones, aunque queda claro que todas se refieren a la misma función y espacio jurisdiccional. Así, se le llama también "cabo principal de las torres de la costa de Poniente del Puerto de Santa María" 32 , o "capitán” de las torres "de la jurisdicción de San Lúcar” ${ }^{33}$, abarcando esta demarcación las mismas torres mencionadas más arriba. La torre del Río del Oro era, según palabras de Mateos, la "última de Arenas Gordas", y por tanto también la última de "las seis torres de la costa de Poniente de mi cargo" ${ }^{34}$. A otros dos personajes que intervienen en este conjunto de comunicaciones sobre la torre del Oro ya los conocemos. Se trata del ingeniero Ignacio de Sala, a quien nos hemos referido antes varias veces; y el conde de Roydeville, capitán general de la Costa de Andalucía. Ambos representan las instancias superiores a las que se dirigen las misivas del requeridor y se hallan en la obligación de dar cauce y solución a los problemas de la torre.

El 13 de marzo de 1748, alarmado por los efectos de los temporales que el litoral acaba de sufrir en el recién pasado invierno, el requeridor Pedro Mateos escribe desde Sanlúcar de Barrameda al capitán general de la Costa para comunicarle su preocupación por el rápido deterioro que están sufriendo las atalayas de la costa almonteńa. Le preocupan estos "continuos temporales" y la "gran ruina" que "estos últimos y tan continuados an ocasionado", como se demuestra en el hecho de que a la torre del Río del Oro le hayan "arrancado más de veinte y ocho baras de zimiento o zapata", dejando al descubierto la mayor parte de esta estructura $^{35}$. La zapata es un elemento clave para la estabilidad del edificio, y es en ella donde se concentran en esta ocasión los mayores desperfectos, pues se halla muy directamente expuesta a la acción del oleaje. A juicio del requeridor Mateos, la situación es tan grave que si llegara a ceder una punta de diamante que refuerza el muro que da al mar, la atalaya corre verdadero riesgo de ruina. Así se lo manifiesta al conde de Roydeville, detallándole que el deterioro se ha producido especialmente en dos puntos, en los que la torre ha perdido "por su banda de Poniente más de veinte varas del zimiento y por la de Levante más de ocho, asta lo profundo". La valoración de Pedro Mateos sobre el estado general de la almenara del Río del Oro no admite dudas: "a quedado la torre en gran peligro porque la ruina será la tersera parte de sus zimientos" 36 .

31 A.C.E.G., C-58, no 1. Relación remitida por el ingeniero Ignacio Salas...1739.

32 A.G.S., Secretaría de Guerra, leg. 3.254.

33 A.C.E.G., C-58, no 1. Relación remitida por el ingeniero Ignacio Salas...1739.

34 A.G.S., Secretaría de Guerra, leg. 3.254. Sanlúcar de Barrameda, 13 de marzo de 1748.

35 Ibidem.

36 Ibidem. 
En el desarrollo de su carta, el responsable de las torres de Arenas Gordas nos aporta una información interesante sobre la evolución del problema en los años precedentes. A pesar de que las que él anuncia en 1748 parecen las primeras noticias conocidas sobre fallos en la cimentación, es muy posible que, al menos una década antes ya se hubieran producido desperfectos comprometedores para la estabilidad de la almenara que estudiamos. Según Mateos, esto ya ocurrió “abrá dose años, [cuando] un temporal le sacó de debaxo quasi la mitad de los fundamentos o cascaxo sobre que se fundó, de modo que al ympetu de las olas temblaba la torre". Sin embargo, un deterioro tan grave solo se mostró de manera transitoria, pues "otro temporal masisó (sic: por macizó) el hueco y quedó al pareser como de antes" ${ }^{37}$. Así, vuelto a cubrir el cimiento de manera natural, el problema quedaba enmascarado, aunque no solucionado. Esto explicaría la ausencia de menciones a la estabilidad en el informe de Sala de 1739, que, de haber observado alguna brecha amenazando la zapata no habría dejado de consignarla. Los nuevos temporales ${ }^{38}$ no hicieron otra cosa que reabrir viejas heridas cerradas en falso.

Sin duda, la situación planteada en la torre del Oro era urgente. En una época como el siglo XVIII en que el sistema administrativo borbónico pretendía caracterizarse por su ordenado y ágil funcionamiento, la maquinaria encargada de garantizar la defensa del territorio se pone pronto en marcha. Sólo 4 días después de la comunicación del requeridor, el director de fortificaciones, Ignacio de Sala, que se encuentra en Cádiz, ya ha tomado cartas en el asunto, remitiendo a su vez una nueva misiva al capitán general Roydeville. En ella le explica cómo ha ordenado ya una visita de las torres almonteńas y en especial de la torre del Río del Oro, pues es preciso efectuar un reconocimiento in situ de los deterioros, tras el cual "se dispondrá el tanteo de su costo, y proyecto si fuese nezesario" 39 . El encargado de este reconocimiento será otro ingeniero, Alonso González de Villamar ${ }^{40}$, aunque Sala señala que es preciso "que passe a aquel sitio un albañil y tres o quatro peones con el citado yngeniero para que se hagan distintas calas al pie de la misma torre", pues lo más importante, dado el problema de socavación

\section{Ibidem}

38 La fuerza de los temporales en los años siguientes no habría de decrecer. En los del año 1750 se registraron pérdidas de vidas humanas, apareciendo tres cuerpos entre las torres de Zalabar y Asperillo. Francisco García García, "Pesca y almadrabas en la costa...", p.134.

39 A.G.S., Secretaría de Guerra, leg. 3.254. Cádiz, 17 de marzo de 1748.

40 Alonso González de Villamar y Quirós ingresa en 1734 en el Cuerpo de Ingenieros, examinado por el ingeniero director Ignacio de Sala. A mediados del siglo se encontraba trabajando en las fortificaciones del litoral gaditano y otros proyectos relacionados con la navegabilidad del río Guadalquivir. Posteriormente desarrolló sus actividades en destinos como Cataluña, Aragón o América. Horacio Capel Sáez y otros, Los ingenieros militares en España. Siglo XVIII. Repertorio biográfico e inventario de su labor cientifica y espacial. Barcelona: Universidad de Barcelona, 1983, pp. 217-218. Y María Gloria Cano Révora, Cádiz y el Real Cuerpo de Ingenieros..., pp. 233-238. 
que sufre la almenara, es que se examine "si su cimiento es de peña o cascajo, lo que penetra el daño que tiene en su fundamento, y si nezesitará de un recalzo" ${ }^{21}$.

La inspección tropieza con alguna dificultad derivada del complicado emplazamiento de la torre, pues "será preciso se execute en baxas mares (sic) de mareas vivas", ya que solamente así sería posible cavar junto a la cimentación de una almenara que en otras circunstancias quedaba rodeada por el mar ${ }^{42}$. Otro de los inconvenientes a solventar iba a ser el económico, siendo preciso allegar los recursos necesarios para abonar los jornales de albañil y peones durante "los dias que estubiesen empleados en ello, como también un bagage para las herramientas", pues la zona es aislada y de comunicación difícil. También es necesario, según Sala, subvenir a los gastos del ingeniero designado para el reconocimiento, "que con su media paga no puede costear semejantes viaxes" ${ }^{33}$. Cierta dificultad para el libramiento de este dinero hace que el asunto pase incluso al conocimiento directo del gobierno de la nación. En efecto, el conde de Roydeville se dirige el 2 de abril de 1748 al marqués de la Ensenada, ministro de Guerra y Marina de Fernando VI, para comunicarle que desde la intendencia de la provincia se entorpece la reparación al no librar las cantidades precisas, amparándose en que las órdenes en vigor no permiten "hazer ningún gasto sin que la Corte lo apruebe" ${ }^{44}$. Este episodio, característico de la centralización administrativa borbónica, dio lugar a una serie de cartas cruzadas que debieron de redundar en la tardanza para aplicar el remedio a una situación que no podía calificarse sino como grave, pues la torre del Río del Oro se encontraba, en palabras de sus responsables directos, "en evidente riesgo de arruinarse" ${ }^{45}$.

No cabe duda de que el segundo plano a que nos venimos refiriendo, el Plano y perfil de la torre del Rio del Oro que demuestra las dos brechas... ${ }^{46}$, corresponde a la situación que acabamos de describir, aunque su fecha, según la ficha catalográfica del Archivo General de Simancas, podría ser ya $1749^{47}$. A pesar de que el citado plano carece de firma o nombre de ingeniero alguno, consideramos lo más probable que sea el producto de la visita de González Villamar, y responde sin dudas a las informaciones suministradas por el requeridor en marzo del año anterior. Así, se muestra gráficamente la zapata de la torre muy dañada por dos

41 A.G.S., Secretaría de Guerra, leg. 3.254. Cádiz, 26 de marzo de 1748.

42 Ibidem.

43 Ibidem.

44 Ibídem. Puerto de Santa María, 2 de abril de 1748.

45 A.G.S., Secretaría de Guerra, leg. 3.254.

46 A.G.S., Mapas, Planos y Dibujos, 56, 030. Plano y perfil de la Torre del Río del Oro...

47 Según la información suministrada por el archivo en la citada ficha, el plano se encuentra “En un expediente de la costa de Poniente. 1749". Por motivos de tipo práctico, nos referiremos a este plano como de dicho año. 
brechas, una "brecha moderna de 12 varas $^{48}$ de largo que a baxado vara y media", situada en el frente oeste; $y$ otra "brecha muy antigua de 15 varas y media de largo cuyas ruinas baxaron como media vara" en la zona sureste. Si seguimos a Pedro Mateos, esta brecha antigua sería la que, tras ser abierta por un temporal hacia 1736, volvió a quedar tapada poco después, dando apariencia de normalidad. Nuevamente abierta por otro temporal, ahora vuelve a preocupar, pues es la mayor de las dos y la que más compromete la estabilidad de la atalaya. Se aprecia cómo ambas brechas están relacionadas directamente con los dos agentes erosivos que desgastan los cimientos de la torre desde sus principios: el arroyo del Oro, ramificado en su desembocadura en una serie de canales que lamen la base de la torre en la bajamar; $y$ las propias aguas marinas, que la circundan completamente en pleamar. El plano es muy preciso sobre este particular, mostrándonos con claridad los niveles máximo y mínimo de las aguas y cómo estas alcanzaban con marea alta el pie mismo de los acantilados. Son, desde luego, especialmente los embates del mar los responsables de las brechas citadas, pues estas se han abierto en el frente marino, azotado constantemente por el oleaje, sobre todo en los temporales invernales.

En el propio título del plano queda ya sugerida la máxima dificultad que habría de tener la reparación de ambas brechas, "muy difíciles de componer por no poderse llegar a descubrir el terreno sólido para cimentar estos reparos". Como se sabe, la ausencia de fundamento sólido donde cimentar las torres fue desde los primeros tiempos un problema clave para sus constructores. Aunque algunas de las atalayas onubenses se vieron libres de esta preocupación, por ubicarse en terreno firme sobre el acantilado costero, otras tuvieron siempre el problema de estar construidas sobre las arenas de islas litorales, puntas arenosas o playas. Es evidente que cualquier recalzo en el cimiento de una edificación de este tipo requería la localización de terreno firme sobre el que asentarlo, cosa que resultaba prácticamente imposible en una torre como la que estudiamos, construida directamente sobre la arena de la playa.

Pero la almenara del Río del Oro era un elemento defensivo verdaderamente indispensable para la seguridad de toda una zona. Así la valoraba en diciembre de 1752 el nuevo capitán general de la costa andaluza, conde de Torre Alta ${ }^{49}$,

48 La vara era una medida de longitud de diferente valor en cada época y lugar. Para la fecha y territorio que estudiamos puede estimarse equivalente a 0,836 metros. Guillermo Duclós Bautista, La fortificación de un territorio..., p. 259.

49 Gabriel José de Zuloaga desempeñó desde 1736 la Capitanía General de Venezuela, donde destacó por su lucha contra el contrabando y por su defensa de diversas plazas frente a los corsarios británicos. Esto le valió en 1744 el título de conde de Torre Alta. Tras su regresó a España en 1747, fue nombrado capitán general de la Costa de Andalucía, y más tarde, miembro del Consejo Supremo de Guerra, puesto que ocupó hasta su muerte en 1763. Luigi Frassato Cambursano, "San Joaquín y los Zuloaga", Mañongo, revista del área de estudios de posgrado de la Universidad de 
en su carta al marqués de Ensenada ${ }^{50}$, donde ponderaba "la conmodidad de su playa, (...) su grandeza y artillería”, así como su capacidad para garantizar la seguridad no solo de las aguas inmediatas, transitadas, como se ha dicho, por abundantes pescadores, sino también la de "los caminantes por las playas de la costa de Poniente", ya que "desde San Lucar o Cádiz hasta Ayamonte, que ay más de 20 leguas de costa, no tienen otro abrigo en aquellos mares las perseguidas de los moros que la torre del Oro". Igualmente, Torre Alta se hacía eco de lo que era un hecho notorio: que las atalayas costeras constituían aún el único medio para obtener noticias sobre la presencia de "embarcaciones de moros u otras enemigas", lo que las hacía necesarias, especialmente en una costa como la de Arenas Gordas, pues "no habiendo en la costa quien dé el aviso, [los enemigos] podrán sin riesgo internar muchas leguas por falta de poblaciones". Por todo ello, y en particular por la importancia de la torre que estudiamos, se hacía evidente la necesidad de "su conserbación o construcción de otras equibalentes" que pudieran reemplazarla.

La opción elegida fue, desde luego, la primera. Una interesante carta del ingeniero Joseph Barnola ${ }^{51}$ al conde de Torre Alta fechada en Cádiz el 24 de octubre de $1752^{52}$ nos informa de la reciente realización de obras en la torre, destinadas en esta ocasión a consolidar la cimentación. Así, el ingeniero indica que "en dos ańos consecutivos se a reparado sus fundamentos y reforzado su pie con un recalzo de cantería". Con ello se había acudido a las urgentes brechas detectadas unos ańos atrás por el requeridor Pedro Mateos, aunque a pesar de ello Barnola estimaba que, "como [la torre] se halla expuesta a los combates continuos del mar, es contingente que en lo subcessivo se destruya", pues esto es lo que "sucede en todas las obras combatidas de este elemento, que es necessario para su conservación grandes dispendios de caudales y vigilancia”. Es la misma idea que aparece en una relación de visita realizada en 1756, en la que su desconocido autor indicaba cómo la experiencia mostraba "ser infructuosos los reparos" en la almenara, a causa de los continuos dańos que se venían registrando ${ }^{53}$.

A pesar de las reparaciones citadas por Barnola, que debemos estimar efectuadas entre los años 1750 y 1752, el conde de Torre Alta comunicaba a

Carabobo (Venezuela), no 23, ańo XII, vol. XII (2004), sin paginar.

50 A.G.S., Secretaría de Guerra, leg. 3.258. Puerto de Santa María, 12 de Diciembre de 1752.

51 El barcelonés Joseph Barnola, colaborador de Ignacio Sala en las obras del arsenal de la Carraca, forma parte en 1749 de la Junta de Fortificaciones de Cádiz, desempeñando el mismo año el cargo de director de las obras de la muralla de esta ciudad. En la década siguiente se ocuparía de algunos proyectos en territorio onubense, como los de los castillos de Puebla de Guzmán y Ayamonte. María Gloria Cano Révora, Cádiz y el Real Cuerpo de Ingenieros..., pp. 101-108.

52 A.G.S., Secretaría de Guerra, leg. 3.258. Cádiz, 24 de octubre de 1752.

53 Relación de las Plazas, Torres, Puestos Fortificados, Edificios Militares y poblaciones de la Costa de Andalucía desde la Raya Occidental del Reino de Granada hasta la de Portugal en Ayamonte según el estado en que se hallan el año 1756. Véase Mora-Figueroa: Torres de almenara..., p. 114-115. 
Ensenada poco después el mal estado general en que seguía la almenara ${ }^{54}$, lo que confirma la enorme dificultad para detener su continuo deterioro. Ante esto, el 19 de diciembre de 1752 el rey emitía una Real Orden para la "renovación", entre otras, de la torre del Río del Oro, disponiéndose que se encargara al ingeniero director la elaboración del "proyecto y tanteo" de la obra ${ }^{55}$. Hacia 1753 debieron de ser redactados, probablemente por el propio Joseph Barnola, dichos proyecto y presupuesto, cuyo resultado fue una reparación general de la torre, y que bien pudo incluir la "gruesa zapata de sillares que abriga su pie" mencionada en la visita de 1756. Si fuera así, habría que concluir que la reparación se efectuó entre estas dos últimas fechas, tratándose de una obra de gran alcance para la solidez de la atalaya.

Ya el profesor Mora-Figueroa, sobre la base únicamente de la citada visita de 1756, había deducido la existencia en los comedios del siglo XVIII de importantes obras destinadas a evitar la ruina de la torre ${ }^{56}$. Así, este investigador proponía que se habrían llevado a cabo en ella dos actuaciones principales. La primera, la colocación de un forro de sillares cubriendo el tercio inferior de la torre, estructura que identifica con la gruesa zapata de sillares antes referida. La segunda, el relleno con ripio y argamasa muy rica en cal de lo que pudo ser, a su juicio, el pozo o aljibe, con el objeto de eliminar un hueco interior que podía comprometer la estabilidad de la almenara. La carta del ingeniero Barnola que hemos citado más arriba confirma el uso de la cantería para reforzar la base de la torre, lo que abona la primera hipótesis de Mora-Figueroa; la segunda parece avalada por la observación directa de los restos conservados, donde pueden apreciarse ciertas porciones de un conglomerado blanquecino no habitual en otros restos de edificaciones similares. Consideramos, con Mora-Figueroa y a la luz de la documentación, que tales obras se llevaron a cabo, y que forman parte de una actuación conjunta, probablemente la proyectada en los primeros años de la segunda mitad del siglo. Para el forro de sillares, que aún se distingue con claridad en el paño mayor conservado de las ruinas, se empleó piedra ostionera, roca sedimentaria marina de gran dureza muy abundante en la costa gaditana ${ }^{57}$. El recalzo cubrió hasta una altura cercana a los 7 metros, hasta un poco más abajo de la puerta.

Una de las cosas que parecían más llamativas a Joseph Barnola era que una torre como la que estudiamos se hubiera construido en un emplazamiento tan poco adecuado para cimentar el edificio. Por ello, en la carta antes mencionada intentaba buscar una explicación razonable, imaginando que tal vez el mar no

54 A.G.S., Secretaría de Guerra, leg. 3.258. 12 de diciembre de 1752.

55 Ibidem. 19 y 26 de diciembre de 1752.

56 Mora-Figueroa: Torres de almenara..., p. 34.

57 La piedra ostionera es un material muy utilizado en la zona en el siglo XVIII, tanto en construcciones civiles como en fortificaciones, baluartes o murallas. Además de su abundancia, entre sus ventajas se encuentran la facilidad de su corte y tallado. 
llegara a su pie en la época de su edificación. Así, creía que en su momento esta almenara, como las demás, debió de levantarse "a una prudente distancia para precaverse de su ruina"; sin embargo, el mar se habría ido "introduciendo más y más" hasta provocar una situación en que la atalaya queda aislada y "solo en baxamar se puede comunicar con ella"58. Tal idea, que es correcta para la mayor parte de las torres que acabaron en contacto con las aguas, no nos parece sin embargo válida para la del Río del Oro, pues esta, como explicaremos en el apartado siguiente, estuvo siempre en contacto directo con el mar. Por otra parte, y al hilo de estas consideraciones, el ingeniero hacía interesantes observaciones sobre la dinámica litoral de la zona. Los efectos del mar sobre la tierra le parecían incomprensibles, pues "en unas partes quita y en otras depone"; observándose todos los años "que los temporales marítimos commovidos (sic) por los vientos del Sur se dirigen a internarse siempre a más a la tierra, profundando donde hallan oposición de murallas y escollos, y explayando las orillas libres de estos obstáculos" 59 . Esta fuerte dinámica contribuiría, según Barnola, a esterilizar cualquier esfuerzo de reparación que se efectuara en el futuro sobre las almenaras existentes.

Sea como fuere, parece que las reparaciones y la "renovación” llevadas a cabo en la torre del Río del Oro en estos años centrales del siglo sirvieron para frenar su deterioro, aunque no se tuviera la certeza de que la situación estuviera salvada por mucho tiempo. En efecto, el visitador de 1756 volvía a mostrar su preocupación por lo expuesto de la construcción a los embates del mar y a la erosión del "arroyo que en las menguantes corre por su pie". En su opinión estaba claro que, "no obstante su robustez" y la potencia de la mencionada zapata, la ruina de la torre sería a la larga inevitable, por lo que adelantaba ya la propuesta de levantar una nueva "tierra adentro, donde carezca de estos accidentes" ${ }^{0}$. Sin embargo, tal cosa nunca llegó a realizarse.

No cabe duda de que, a pesar de la negativa visión sobre el futuro de la torre expresada por Joseph Barnola y por el visitador de 1756, las obras resultaron satisfactorias al menos por un cierto tiempo. En 1764 un ingeniero tan acreditado como Antonio de Gaver se refería a la atalaya como "cituada a la orilla del mar y construida de buen material, no necesitando de reparo alguno" ${ }^{61}$. Probablemente

58 A.G.S., Secretaría de Guerra, leg. 3.258. Cádiz, 24 de octubre de 1752.

59 Ibidem.

60 Relación de las Plazas, Torres, Puestos Fortificados... Mora-Figueroa: Torres de almenara..., p. 114-115. Resulta llamativo que, solo un año después del maremoto de 1755, el visitador no haga referencia a dańos causados por este fenómeno. Hay que concluir que no se produjeron más de los habituales por los temporales marítimos ordinarios.

61 A.G.S., Secretaría de Guerra, leg. 3.263. Relación del estado en que se hallan las baterías y torres situadas en la costa de Poniente del departamento del Puerto de Santa María a mi cargo y comprehende desde esta ciudad hasta la torre del arroyo del Oro, distando doze leguas de Ayamonte, con 
llamó su atención el sólido aspecto del recalzo de sillares que cubría el tercio inferior, solidez que estaba en consonancia con su idea de montar sobre el terrado de la almenara "quatro cañones de qualquier calibre". La torre, atendida por tres torreros y tres artilleros, sigue en estos ańos prestando servicio con normalidad, aunque una de las circunstancias que más va a preocupar ahora será su lejanía con respecto a la atalaya más cercana por poniente: la torre de la Arenilla ${ }^{62}$.

Esa es precisamente la preocupación que expresa el mismo ingeniero en un nuevo informe que completa a un detallado mapa suyo elaborado en $1768^{63}$. Aunque la torre recibe la calificación de "en buen estado", Gaver hace notar "las quatro leguas de distancia que hai (sin descubierta, y donde se interrumpen las ahumadas) desde la torre del Oro a la de la Arenilla”. Una prueba de que las señales seguían haciéndose de manera regular durante el siglo XVIII nos la suministra el párroco de Almonte en su respuesta de 1785 al geógrafo Tomás López. Al hablar de las seis atalayas de este término municipal, no se olvida de reseñar que en ellas "residen diariamente dos torreros para encender a las alboradas las luminarias" ${ }^{64}$. Por ello, la existencia de un amplio tramo sin cubrir, como el declarado por Gaver, constituía un serio inconveniente para la continuidad de las señales y entorpecía notablemente la tarea de "vigiar y avisar a nuestras embarcaciones de los corsarios" "65. Como hemos mostrado en anteriores trabajos ${ }^{66}$, en la mediación de este extenso tramo litoral existió antiguamente otra torre almenara, la de Morla, cuya pronta desaparición ocasionó por mucho tiempo una discontinuidad en el sistema de avisos, si bien su lugar era suplido habitualmente por chozas u otros puestos desde donde servían los torreros. Al parecer, y según el propio Antonio de Gaver, ya en 1768 existía un proyecto para construir una atalaya en la "Punta del Picacho", probablemente no muy lejos de donde se alzó en su tiempo la vieja torre de Morla.

A pesar de estas limitaciones para la transmisión de las señales y de las dificultades arquitectónicas ya comentadas, la torre del Río del Oro parece haberse mantenido en el siglo XVIII en un correcto estado de defensa, conservando casi siempre artillería en buen uso y personal específico para su manejo. Así, después

las obras mayores y reparos que se necessitan para evitar maiores daños y quedar en estado de defensa. Puerto de Santa María, 18 de diciembre de 1764. Por Antonio de Gaver.

62 Entre ambas torres se extiende un largo tramo de costa de 22 kilómetros, mientras que desde la del Oro hasta su desaparecida vecina del Asperillo solo había 5. La distancia media entre las almenaras onubenses puede estimarse en 9,5 kilómetros.

63 A.G.S., Mapas, Planos y Dibujos, 50, 004. Plano de la costa de Andalucía desde Ayamonte hasta el río Guadiaro. 1768. Por Antonio de Gaver.

64 Juan Enrique Ruiz González, Los pueblos de Huelva en el siglo XVIII (según el Diccionario del Geógrafo Real D. Tomás López). Huelva: Diputación Provincial, 1999, p. 48.

65 A.G.S., Mapas, Planos y Dibujos, 50, 004. Plano de la costa de Andalucía desde Ayamonte... 1768. Por Antonio de Gaver.

66 Véase nota $n^{\circ} 7$. 
del informe de Ignacio de Sala, que indicaba estar los cañones desmontados y ser necesario rehabilitar la capacidad artillera de la almenara ${ }^{67}$, encontramos que tal consejo debió de ser seguido, pues en 1756 contaba con tres cañones de hierro de los calibres 12,8 y 6 , además de dos artilleros para su servicio ${ }^{68}$. El mismo número de cañones tenía en 1764, aunque eran los tres del calibre 12, proponiendo el ingeniero Antonio de Gaver incrementar en uno la dotación; también contaba entonces con un artillero más ${ }^{69}$.

Así, en un aceptable estado de uso, no exento de la permanente duda sobre su estabilidad, parece haberse mantenido a lo largo del siglo XVIII la torre del Río del Oro. Y así continuó hasta la fecha, no concretada aún, de su colapso ${ }^{70}$. Algunos de los ingenieros o inspectores que la visitaron en el siglo XIX insistieron en la necesidad de prescindir de la almenara y reedificar una nueva más hacia el interior, alejada de las aguas ${ }^{71}$. Sin embrago, la torre resistió todavía, aunque posiblemente dañada, durante bastante tiempo gracias a su robustez. En 1827 el diccionario de Sebastián de Miñano podía aún referirse a ella como una almenara activa, "de figura circular, de 16 varas de diámetro, 18 de altura, (...) y situada en playa baja, de modo que queda aislada en la pleamar" ${ }^{\text {". }}$. Aunque no contamos con un dato preciso sobre el momento de su destrucción, en 1867 un derrotero de la costa ya la presenta "casi en ruinas", de forma que "de lejos se parece a una escollera, o más bien a una embarcación varada"73. Tantos años entre aguas y arenas habían por fin vencido a los debilitados cimientos de una torre que, a la vista de los antecedentes expuestos y de la posición de los restos conservados, se arruinó de manera muy diferente a sus vecinas del Asperillo o

67 A.C.E.G., C-58, no 1 . Relación remitida por el ingeniero Ignacio Salas...1739.

68 Relación de las Plazas, Torres, Puestos Fortificados... Mora-Figueroa: Torres de almenara..., p. 115.

69 A.G.S., Secretaría de Guerra, leg. 3.263. Relación del estado en que se hallan las baterías y torres situadas en la costa de Poniente... Puerto de Santa María, 18 de diciembre de 1764. Por Antonio de Gaver.

$70 \mathrm{Ni}$ en el caso de la torre del Río del Oro ni en el de las otras almenaras onubenses destruidas puede aceptarse como causa de la destrucción el Terremoto de Lisboa de 1755, como proponen algunos trabajos, entre ellos el de José Carlos Salcedo Hernández y Antonio José Campesino Fernández, "El paisaje de las torres de almenara de la costa onubense, tras el sismo de Lisboa (1755)", 20 Seminario Internacional "Arquitecturas do Mar e filosofía e arquitectura da paisagem". Lisboa: Faculdade de Arquitectura da Universidade Técnica de Lisboa (Centro de Investigaçao em Arquitectura, Urbanismo e Design, 2012. Disponible en www.uexgica.blogspot.com.es/p/ resultados-de-investigacion-2012.html

71 Juan Villegas Martín y Antonio Mira Toscano, "La defensa de la costa onubense en las primeras décadas del siglo XIX”, Aestuaria, no 11 (2010), pp. 77-120.

72 Sebastián de Miñano Y Bedoya, Diccionario Geográfico-Estadístico de España y Portugal, tomo VIII. Madrid: Imprenta de Pierart-Peralta, 1827, p 237.

73 Pedro Riudavets y Tudury, Derrotero de las costas de España y de Portugal desde el cabo Trafalgar hasta el puerto de La Coruña. Madrid: Dirección de Hidrografía, 1867, p. 154. 
de la Higuera. Estas, emplazadas en lo alto de sus correspondientes acantilados, fueron víctimas de la erosión los mismos; la del Oro, situada en la parte baja de la playa, se resquebrajó y se partió en varios fragmentos ante el agravamiento de los fallos de cimentación.

\section{4. ¿Cómo era la torre del Río del Oro?}

Además de informarnos sobre los desperfectos, obras y reparaciones de la torre del Río del Oro en el siglo XVIII, los planos y documentos que analizamos en este artículo presentan otro frente de especial interés, puesto que constituyen los mejores medios a nuestro alcance para hacernos una idea de la morfología y características de una torre cuyo estado de completa ruina desde el siglo XIX nos ha privado hasta ahora de contar con informaciones fiables en tal sentido. Ya sabíamos por los documentos de la época de su construcción que la almenara del Río del Oro era una de las más especiales, si no la más especial, de cuantas acabaron por levantarse en el litoral onubense. Para Mora-Figueroa, que fotografió sus restos en 1976, era una de las torres arqueológicamente más interesantes de esta $\operatorname{costa}^{74}$, cosa que confirman la planimetría y la documentación que tratamos en este trabajo. Del análisis de estas fuentes podemos deducir bastantes aspectos hasta ahora no conocidos sobre su estructura y características constructivas.

Tal vez el elemento más determinante para este conocimiento es el ya estudiado Plano y perfil de la Torre del Rio del Oro que demuestra las dos brechas... ${ }^{75}$. Sujeto, como corresponde a la planimetría del siglo XVIII, a una aplicación rigurosa de las escalas, sus informaciones parecen suficientemente fiables, presentando una planta y sección de la atalaya anteriores a las reparaciones realizadas hacia 1750 de cuya interpretación podemos deducir muchos datos sobre el estado original de la torre. Sobre la base de estas representaciones, que hemos comparado con las informaciones escritas proporcionadas por las relaciones de Ignacio de Sala y Antonio de Gaver, podemos señalar las siguientes características de la atalaya ${ }^{76}$ :

74 Mora-Figueroa: Torres de almenara..., p. 35.

75 A.G.S., Mapas, Planos y Dibujos, 56, 030. Plano y perfil de la Torre del Río del Oro...

76 Las medidas resultantes de la interpretación de estas fuentes no son enteramente coincidentes. Ello podría deberse a que hayan sido tomadas o no contando con la zapata de cimentación y a la acumulación de arenas sobre esta en cada momento. En la altura total de la torre entendemos que se exceptúa la garita de salida de la escalera. 


\begin{tabular}{|c|c|c|c|c|c|c|}
\hline \multirow[t]{2}{*}{$\begin{array}{l}\text { Características de la torre del } \\
\text { Río del Oro } \\
\text { (Elaboración propia a partir de } \\
\text { los documentos indicados) }\end{array}$} & \multicolumn{2}{|c|}{$\begin{array}{c}\text { Relación de } \\
\text { Ignacio de Sala } \\
\text { (A.C.E.G., C-58, no1) } \\
\text { Año } 1739\end{array}$} & \multicolumn{2}{|c|}{$\begin{array}{c}\text { Plano del A.G.S., } \\
\text { (M.P.D., 56, 030) } \\
\text { Año } 1749\end{array}$} & \multicolumn{2}{|c|}{$\begin{array}{c}\text { Relación de } \\
\text { Antonio de Gaver } \\
\text { (A.G.S., } \\
\text { Secretaría Guerra, } \\
\text { leg. } 3.263 \text { ) } \\
\text { Año } 1764\end{array}$} \\
\hline & Tuesas & Metros & Varas & Metros & Tuesas & Metros \\
\hline Diámetro en la base & 6 & 11,70 & 17,5 & 14,63 & 7 & 13,65 \\
\hline Diámetro en el terrado & - & - & 15 & 12,54 & - & - \\
\hline $\begin{array}{l}\text { Altura desde los cimientos } \\
\text { hasta el comienzo de la puerta }\end{array}$ & 3 & 5,85 & 8 & 6,69 & - & - \\
\hline $\begin{array}{l}\text { Altura máxima } \\
\text { de la bóveda inferior }\end{array}$ & - & - & 6,5 & 5,43 & - & - \\
\hline $\begin{array}{l}\text { Altura máxima } \\
\text { de la bóveda superior }\end{array}$ & - & - & 4,5 & 3,76 & - & - \\
\hline Altura del pretil del terrado & - & - & 1 & 0,83 & - & - \\
\hline Altura total de la torre & 8,5 & 16,57 & 22 & 18,39 & 8 & 15,60 \\
\hline
\end{tabular}

En primer lugar, y aunque por algunos datos colaterales ya podíamos intuir el mayor tamaño de esta torre con respecto a otras, hasta ahora desconocíamos realmente sus grandes dimensiones. Los entre 16 y 18 metros de altura total que debía de alcanzar la convierten, junto a la de Canela, en la almenara de mayor envergadura de la costa onubense. Un dato desconocido hasta ahora es que se trataba de una torre de doble cámara. Así lo manifiesta la anteriormente citada relación de Ignacio de Sala: "tiene sus dos bóvedas y su caracol para subir a la esplanada" "7; y así lo confirma la sección longitudinal del plano de 1749, donde quedan dibujadas con claridad ambas cámaras. Hay que recordar que esta tipología fue la preferida desde los primeros momentos para aquellas almenaras que debían montar artillería, como indican algunos documentos ya conocidos en que las torres artilladas se distinguían con el calificativo de "buenas" o "muy buenas" frente al de "ordinarias" que se daba a las simples atalayas de vigilancia ${ }^{78}$. Y así se ejecutó finalmente ${ }^{79}$, con la sola excepción de la torre de San Jacinto, artillada pero de una sola cámara. La que nos ocupa, proyectada desde

77 A.C.E.G., C-58, no 1. Relación remitida por el ingeniero Ignacio Salas...1739.

78 A.G.S., Guerra Antigua, leg. 155/10. Relación de las torres que paresçe aver menester... Sin fecha, aunque esta debe estimarse en torno a 1583. Mora-Figueroa, Torres de almenara..., p. 89-90.

79 Nos referimos al momento inicial de puesta en funcionamiento del sistema de las torres. A.G.S., Mar y Tierra, leg. 819. Relación de las torres que hay en la costa del mar de Andalucía... Año 1616. 
estas primeras visitas como "torre muy buena" ${ }^{\circ 0}$, siempre aparece en estas fechas como torre artillada, aunque es conocido que la dotación inicial que recibió fue inutilizada por un ataque pirata al poco tiempo de su construcción ${ }^{81}$.

Como es habitual en este tipo de torres vigías, la puerta de acceso se encontraba en la cara contraria al mar, a casi 7 metros de altura, de manera que eran necesarias escalas de cuerda o madera para subir, las cuales se retiraban luego para impedir la entrada a visitantes indeseados. A la primera cámara, cubierta con bóveda de media naranja, se accedía por medio de un corredor o zaguán de unos 3,8 metros de longitud, distancia coincidente con la potencia de muro de la torre. La cámara era un espacio circular diáfano de más de 6 metros de diámetro. Aunque al ingeniero Ignacio de Sala la torre le pareció maciza hasta la altura de la puerta, a la vista del perfil dibujado en el plano de 1749 y de algunas evidencias materiales podemos concluir lo contrario. El citado plano representa un gran hueco interior que, ocupando toda la circunferencia interna de la torre, se extiende desde los cimientos hasta la bóveda de la primera cámara. El suelo de esta aparece insinuado, cortando horizontalmente en dos dicho hueco, en lo que podría ser un piso de madera. Entre los restos de la torre, en el paño mayor de los conservados, puede observarse parte de la cara interna del tercio inferior, indudablemente hueco, aunque, como hemos señalado, se rellenó más tarde para dar solidez a la atalaya. Todo apunta a que este espacio había sido anteriormente el aljibe de la torre. Otro elemento visible en el conjunto de los restos apoya la idea de que el suelo de la cámara fuera de madera. Se trata de una especie de murete de piedra que se conserva muy deteriorado adherido a los rellenos blanquecinos desprendidos hacia el Este; parece que pudo corresponder a una compartimentación interior del hueco del aljibe y que debió de servir para apoyar en el centro de la cámara la hipotética tablazón del piso.

Dentro de la primera cámara, a la derecha del zaguán de entrada, se abría la escalera que permitía el acceso a la cámara superior y al terrado. Construido dentro del muro de mampuestos, el caracol medía aproximadamente 1,5 metros de radio, siendo su tramo inferior en la actualidad uno de los elementos más visibles entre los restos conservados de la torre. La disposición de la escalera a la derecha del zaguán nos acerca al modelo de otras almenaras vecinas, como las de San Jacinto, Carbonera o Zalabar, con quienes comparte también la tipología de los peldańos, labrados en una sola pieza de piedra ${ }^{82}$.

Por motivos defensivos no parece que hayan existido ventanas en los muros de la torre, con lo que la ventilación e iluminación quedaban confiados a los huecos

80 A.G.S., Guerra Antigua, leg. 155/10. Relación de las torres que paresşe aver menester.. MoraFigueroa, Torres de almenara..., p. 89-90.

81 Mora-Figueroa, Torres de almenara..., p. 112.

82 Ibidem, p. 70. 
de la puerta, cuando estaba abierta, y la escalera. Aunque no hay seguridad, es muy posible que para dar paso a la luz solar se usara, como en otras atalayas onubenses, un pequeño orificio practicado en las claves de las bóvedas. Dicho orificio podría servir también, en su caso, para dejar paso al agua de lluvia hasta el hipotético aljibe situado en el cuerpo bajo de la torre.

La explanada superior, donde irían montados los cañones y desde donde se harían las señales, contaba con un pretil bajo y corrido de unos 80 centímetros de alto por otro tanto de ancho. No se indica en la planta que tuviera ningún tipo de almenas o troneras, a pesar de contar con artillería ${ }^{83}$. Marcando el inicio de esta merlatura corrida, por la parte exterior, la torre presentaba el característico baquetón de medio bocel, posiblemente labrado en piedra. Lo más probable es que, en su primera construcción, contara con la habitual buhedera o ladronera para la defensa de la puerta, sobresaliendo por encima del pretil del terrado. No aparece esta estructura en los planos que manejamos, posiblemente porque pudo ser eliminada en las obras posteriores a la visita de 1739. Como ya hemos explicado, creemos que estas obras consistieron en la construcción de una gran garita que ocuparía la mitad del terrado y que aparece representada en el plano de 1749. Destinada entre otras cosas a albergar la salida de la escalera de caracol, pensamos que esta construcción hizo también eliminar una garita anterior, seguramente mucho más pequeña y acorde con los modelos aún visibles en otras torres ${ }^{84}$. Es llamativo que la puerta de salida de la nueva estancia hacia el terrado se encontrara rebajada con respecto a la cara exterior del muro; posiblemente este retranqueo respondía a la necesidad de no tapar el hueco de entrada de la luz exterior o agua de lluvia, situado justo en el centro de la explanada de la torre.

Uno de los aspectos más destacables que la nueva documentación nos permite aclarar sobre la torre del Río del Oro, y que también se ha avanzado en el apartado anterior, es el emplazamiento del edificio. Aunque en ocasiones, por similitud con otras torres destruidas de las inmediaciones, se ha supuesto que pudo haberse levantado en la parte superior de la terraza cercana y que, erosionada esta, habría caído a la playa ${ }^{85}$, no cabe duda de que la atalaya siempre estuvo donde hoy se hallan sus restos, es decir, en plena orilla y en contacto con el agua ${ }^{86}$. Así lo

83 Otra torre artillada, la de Punta Umbría, comparte esta característica con la que estudiamos. Sí disponen de un pretil con almenas artilleras las de San Jacinto y Canela.

84 Como por ejemplo las existentes en las atalayas de Canela o El Catalán.

85 Salcedo y Campesino, "El paisaje de las torres de almenara...", p. 19.

86 Como señalan algunos estudios sobre geomorfología costera, las torres de almenara constituyen un punto de referencia para conocer la situación de la antigua línea litoral y sus transformaciones. Así, la posición de los restos de las torres de la Higuera o El Asperillo las convierten en testimonio de una acusada retrogradación litoral; sin embargo, este no es el caso del Río del Oro, cuya torre no se alzaba sobre la terraza costera. Esto, junto a la planimetría que publicamos, nos permite afirmar, contrariamente a lo que sostienen otros autores, que en este punto no se ha producido un avance significativo del mar desde mediados del siglo XVIII. A. Rodríguez Ramírez, 
demuestran tanto los dos planos que publicamos como diversas referencias que pueden extraerse de la documentación adjunta. La carta del requeridor Mateos en marzo de 1748 deja claro que "la torre del Río del Oro está situada en la lengua del agua de modo que a las cresientes queda yslada, batiendo en ella el mar" ${ }^{87}$. También la vio así el ingeniero Joseph Barnola en octubre de 1752, "expuesta a los combates continuos del mar", si bien creyó que se encontraba en tal situación por haber avanzado las aguas sobre la costa en este punto ${ }^{88}$. Pero Barnola desconocía que ya en la época de su planificación, a finales del siglo XVI, los ingenieros habían previsto que la atalaya fuera construida en plena orilla. La elección de tan arriesgada ubicación tuvo muy probablemente un motivo político, desdeñando los consejos de la experiencia arquitectónica y militar. Desde al menos 1584 se había decidido que la almenara se financiaría a medias entre el Duque de Medina Sidonia y el Conde de Miranda, situándose a caballo entre sus dos señoríos ${ }^{89}$. Siendo su frontera la desembocadura del Río del Oro, tal designio obligaba a que la torre se construyera sobre el arroyo, descartando cualquiera de las dos laderas inmediatas por ser tierra de uno u otro señor. También era inviable la parte interior de la garganta, pues allí la torre sería inútil. Así, sólo quedaba la playa, aunque alzar un edificio de este calibre sobre las arenas y con la seguridad de que el mar combatiría sus cimientos supusiera un verdadero reto para los constructores. En efecto, ello obligaba a un alarde constructivo importante, pero no imposible en aquella fecha. Hay que recordar los tratados de finales del siglo XVI del ingeniero Cristóbal de Rojas, que mostraban la manera de construir sobre suelos pantanosos o incluso sobre el agua utilizando sistemas de pilotaje ${ }^{90}$. Sabemos del uso de pilotes al menos en una de las torres onubenses, la de Canela ${ }^{91}$, por lo que no sería extraño que se hubieran empleado también en el caso que nos ocupa, aunque no existen evidencias documentales ni materiales en tal sentido.

L.M. Cáceres, J. Rodríguez Vidal, E. Flores, M. Cantano y V. Guerrero, "Cambios morfológicos y tasas recientes de erosión-depósito en la costa atlántica oriental de Huelva (España)”, Geogaceta, n ${ }^{\circ}$ 21. (1997), pp. 187-189.

87 A.G.S., Secretaría de Guerra, leg. 3.254. Sanlúcar de Barrameda, 13 de Marzo de 1748.

88 Ibidem, leg. 3.258. Cádiz, 24 de octubre de 1752.

89 S(ección) N(obleza) A(rchivo) H(istórico) N(acional), Osuna, C. 382, D. 58.

90 Cristóbal de Rojas, Teórica y práctica de fortificación, conforme las medidas y defensas destos tiempos, repartida en tres partes. Madrid: Luis Sánchez, 1598. Tercera parte, capítulo V: "De los fundamentos sobre arena en el agua, arcilla, tufa, o en peña biva". Véase también Ángel J. SÁEZ RODRÍGUEZ, "El ingeniero Cristóbal del Rojas reconoce Tarifa en 1597 (I)", Aljaranda, revista de estudios tarifeños, $\mathrm{n}^{\circ} 51$ (2003), pp. 4-7. En este trabajo se insertan dos grabados tomados de las obras de Rojas donde se representan una máquina para clavar pilotes y una torre cimentada con este sistema.

91 Antonio Mira Toscano y Juan Villegas Martín, "La torre de Canela, una almenara del siglo XVII", en Enrique Arroyo Berrones (ed.): Actas de las XIII Jornadas de Historia de Ayamonte, Ayamonte: Ayuntamiento de Ayamonte, Área de Cultura, 2009, pp. 47-74. 
Indudablemente, un emplazamiento tan osado hubo de ser contrarrestado con una serie de elementos constructivos especialmente destinados a dotar a la atalaya de la necesaria solidez, unos habituales en las torres de la costa de Huelva, otros completamente singulares. Entre los habituales, hay que citar la zapata, que, en palabras de Pedro Mateos "crese afuera de la torre más de una bara y profunda más de dos" ${ }^{\prime 2}$. La mayor parte de las torres de almenara contaban con una zapata ${ }^{93}$, estructura que proporcionaba una base sólida a la construcción y le daba consistencia en caso de no contarse con terreno firme. Insinuada en el plano de 1742, esta estructura aparece dibujada con detalle en el de 1749, donde se señalan sus daños. Las alusiones posteriores se refieren probablemente al recalzo de sillares con que se reforzó la base de la torre a mediados del siglo XVIII.

Pero la torre del Río del Oro disponía de elementos de solidez muy singulares, totalmente inexistentes en cualquiera de las restantes torres del litoral onubense. La documentación nos informa de que "fortifican su zimiento dos contrafuertes o puntas de diamante, una a tierr (sic) y otra al mar de norte a zur" ${ }^{\prime 4}$. Se trata, en efecto, de dos puntas construidas en piedra y destinadas a aliviar al muro de la acometida de las aguas, sobresaliendo en su vértice dos metros sobre la circunferencia de la torre. Ambos contrafuertes aparecen representados en el plano de 1749 pero no en el de 1742 . Tal vez este último plano, poco pormenorizado en lo que respecta a la torre, omitió este detalle por considerarlo irrelevante. Cabe no obstante otra posibilidad: que estas puntas de diamante no sean originales y fueran añadidas entre ambas fechas, en el curso de alguna obra de refuerzo y consolidación de la torre. El contrafuerte más castigado fue, lógicamente, el que defendía el frente marino, de manera que en los temporales de mediados del siglo quedó flanqueado por brechas a derecha e izquierda; a pesar de ello se mantuvo "el contrafuerte o punta en que bate el mar", siendo tan importante su conservación que "si flaquea la punta de diamante [la torre] tiene gran peligro de caer o arruinarse" 95 . Del segundo contrafuerte, enfrentado a las aguas vertientes del Río del Oro, puede aún apreciarse el arranque en la parte baja del lienzo mayor conservado ${ }^{96}$.

Hasta aquí lo que hemos podido conocer por el momento sobre una de las almenaras más interesantes de la costa onubense. La planimetría y la documentación recientemente localizadas nos han permitido adentrarnos un poco más en su morfología y su historia, ofreciéndonos la posibilidad de acercarnos, siquiera de forma aproximada, a la configuración de una torre que anteriormente

92 A.G.S., Secretaría de Guerra, leg. 3.254. Sanlúcar de Barrameda, 13 de Marzo de 1748.

93 La maltrecha almenara de la Higuera, en posición invertida desde al menos 1739, nos permite observar el aspecto de su potente zapata, hoy en la parte superior. Véase nota $\mathrm{n}^{\circ} 70$.

94 A.G.S., Secretaría de Guerra, leg. 3.254. Sanlúcar de Barrameda, 13 de Marzo de 1748.

95 Ibidem.

96 Véase figura 4. 


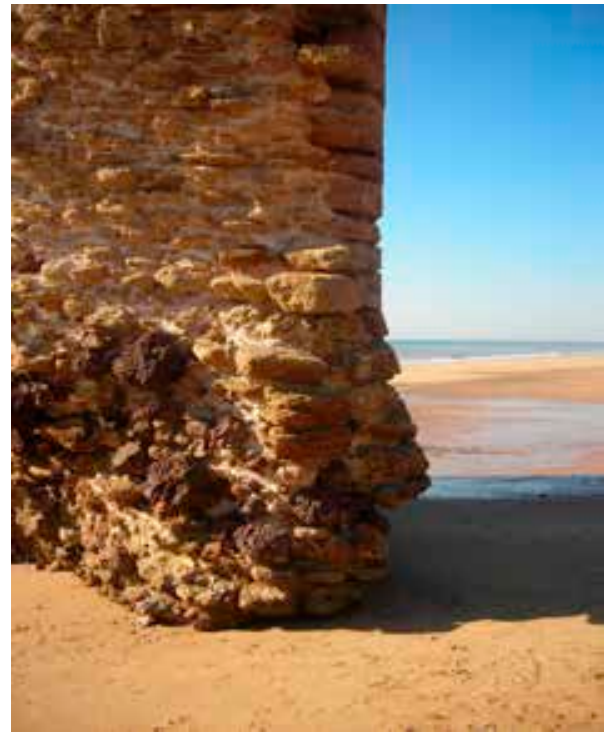

Figura 4. Arranque, muy deteriorado, de uno de los contrafuertes o puntas de diamante que reforzaban la zapata de la torre (fotografía de los autores).

se nos aparecía solo como una informe masa de ruinas. Pero, aparte de lo que las fuentes gráficas o escritas puedan aportar en el futuro, son los propios restos de la torre los que, con la intervención de la arqueología, deben aclarar aún muchas incógnitas. Y esto es así porque la torre del Oro nos ofrece la excelente oportunidad de contemplar aquello que fue construido para quedar oculto, de asomarnos al interior de muros o estructuras ya derruidas para investigar con detalle los pormenores del sistema constructivo. Para ello, sin embargo, es necesaria una condición fundamental, cual es la adecuada preservación de estos restos. Por desgracia, cualquier visitante que se acerque a la torre y compruebe el grado de erosión de los lienzos conservados tiene fácilmente la impresión de que,
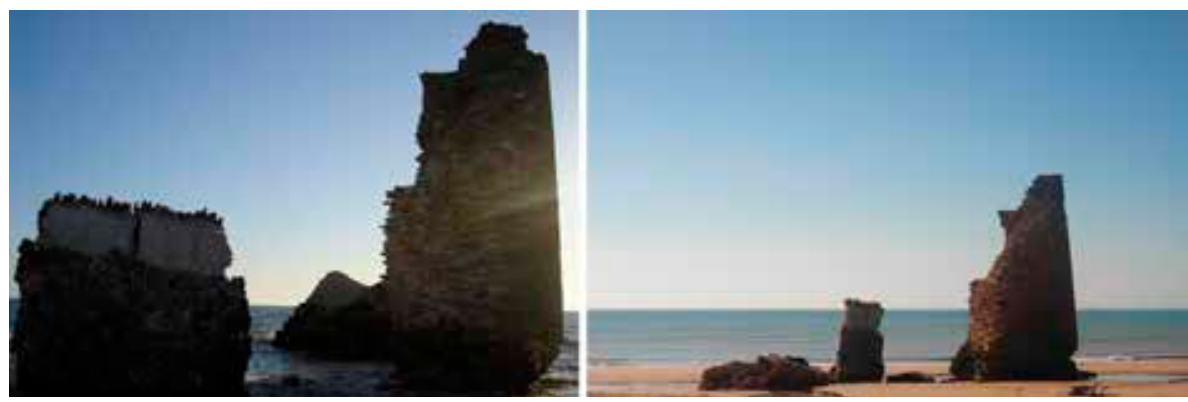

Figura 5. Imágenes que muestran la reciente fragmentación de uno de los bloques conservados de la torre (fotografías de Antonio Delgado Pinto y de los autores). 
si no se toman medidas urgentes, el mar se encargará pronto de impedir que la vieja torre nos legue sus secretos ${ }^{97}$.

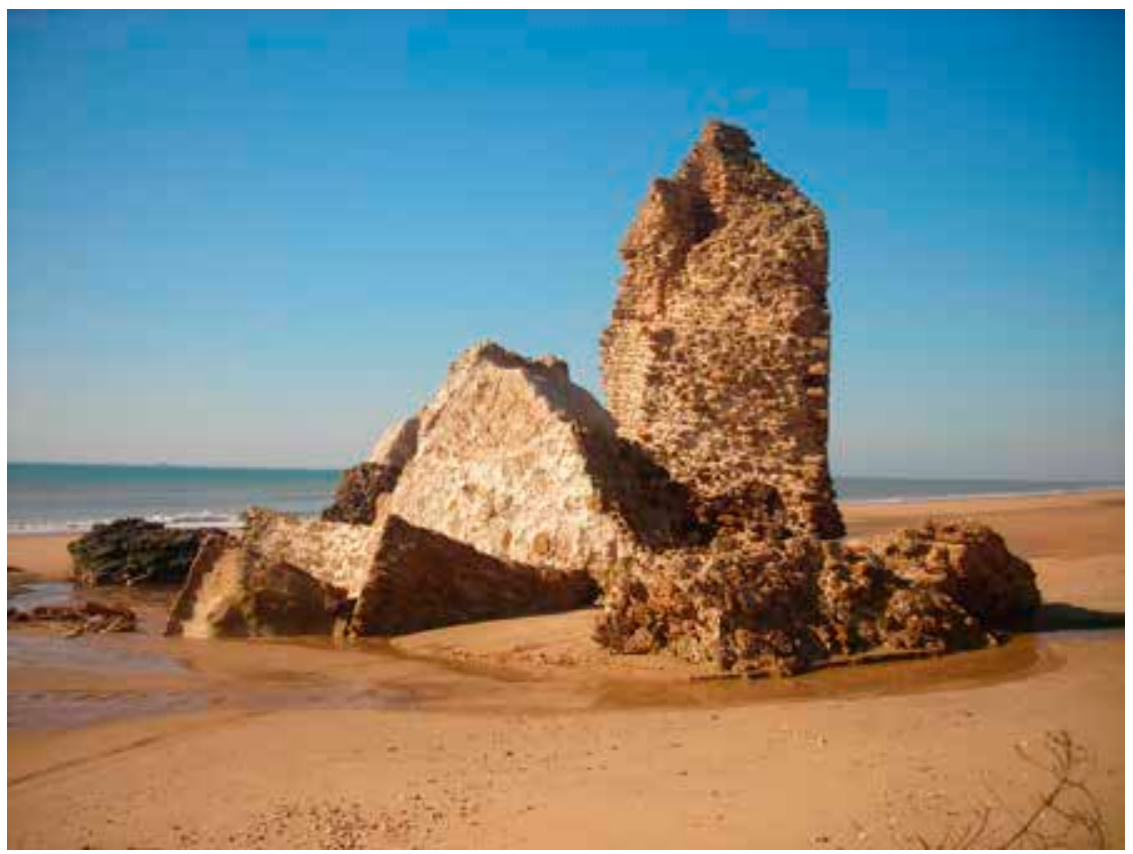

Figura 6. Aspecto de los restos de la torre del Río del Oro con el bloque fragmentado en primer plano (fotografía de los autores).

97 La fragmentación de los restos continúa, como pudimos apreciar en una de nuestras visitas a la torre, efectuada en diciembre de 2007. En el invierno anterior y por efecto de los temporales, el bloque situado al este del lienzo mayor se había dividido en dos partes. Véase figuras 5 y 6. 


\section{Documentos}

A) Carta de Pedro Mateos, requeridor de las torres de Poniente, al capitán general de la Costa de Andalucía, conde de Roydeville.

Sanlúcar de Barrameda, 13 de Marzo de 1748.

A.G.S., Secretaría de Guerra, leg. 3.254

Excelentísimo Señor

Señor:

Con los continuos temporales se ban arruinando cada bes más las seis torres de la costa de Poniente de mi cargo; pero estos últimos y tan continuados an ocasionado gran ruina pues a la torre del Río del Oro, última de Arenas Gordas, le a arrancado más de veinte y ocho baras de zimiento o zapata, en esta forma:

La torre del Río del Oro está situada en la lengua del agua de modo que a las cresientes queda yslada, batiendo en ella el mar; y fortifican su zimiento dos contrafuertes o puntas de diamante, una a tierr (sic) y otra al mar de norte a zur, y abrá dose años que un temporal le sacó de debaxo quasi la mitad de los fundamentos o cascaxo sobre que se fundó de modo que al ympetu de las olas temblaba la torre; y otro temporal masisó (sic: por macizó) el hueco y quedó al pareser como de antes, hasta que aora estos temporales abiéndole descubierto la maior parte del zimiento o zapata, que crese afuera de la torre más de una bara y profunda más de dos; manteniéndose el contrafuerte o punta en que bate el mar, le arrancó por su banda de Poniente más de veinte baras del zimiento y por la de Levante más de ocho, asta lo profundo y a quedado la torre en gran peligro porque la ruina será la tersera parte de sus zimientos; y si flaquea la punta de diamante tiene gran peligro de caer o arruinarse.

Señor, desde la barra de esta ziudad asta la de Huelva no ay más fortalesa que la de esta torre que por su grandesa y hartillería es lo que respectan los moros en aquella costa, y es el assilo de las embarcaciones que hordinariamente persiguen, todo lo qual (en fuerza de mi obligasión) pongo en la considerasión de Vuestra Excelencia para que se digne mandar lo que Vuestra Excelencia tenga por combeniente.

Nuestro Señor guarde la persona de Vuestra Excelencia muchos años como puede. Sanlúcar de Barrameda, 13 de marzo de 1748.

Excelentísimo Señor.

Señor.

Besa los pies de Vuestra Excelencia su más reconocido súbdito.

Don Pedro Matheos (rúbrica)

Excelentísimo Señor conde de Leroy De Ville. 
B) Carta del ingeniero Ignacio de Sala al capitán general de la Costa de Andalucía, conde de Roydeville.

Cádiz, 26 de Marzo de 1748.

A.G.S., Secretaría de Guerra, leg. 3.254

Excelentísimo Señor.

Mui Señor mío:

En consequencia de la orden de Vuestra Excelencia devo decir que aunque e destinado al yngeniero don Alonso González de Villamar para hazer el reconocimiento de las torres de Poniente, y con especialidad la torre del Río del Oro, cuyo fundamento a socavado el mar según el aviso de don Pedro Matheos, requeridor de ellas, es preciso que passe a aquel sitio un albañil y tres o quatro peones, con el citado yngeniero, para que se hagan distintas calas al pie de la misma torre, se examine si su cimiento es de peña o cascajo, lo que penetra el daño que tiene en su fundamento, y si nezesitará de un recalzo, a fin de formar un estado individual de la obra que se deverá hazer para seguridad de la sobredicha torre y el coste que podrá tener.

$\mathrm{Al}$ albañil y peones que an de pasar a este reconocimiento (que será preciso se execute en baxas mares de mareas vivas) se les deverán pagar sus jornales los días que estubiesen empleados en ello, como también un bagage para las herramientas; por lo que me pareze combeniente se sirva Vuestra Excelencia escrivir al yntendente a fin de que destine el caudal nezesario para estos jornales; y también en concideración de los atrasos del sobredicho yngeniero don Alonso González, que con su media paga no puede costear semejantes viaxes, se sirva al mismo tiempo librarle algún socorro; que es quanto se me ofreze hazer presente a Vuestra Excelencia sobre este asumpto.

Dios guarde a Vuestra Excelencia los más años que deseo. Cádiz, 26 de marzo de 1748 .

Excelentísimo Señor.

Beso las manos de Vuestra Excelencia.

Su más seguro servidor.

Don Ignacio Sala (rúbrica)

Excelentísimo Señor conde Le Roydeville. 
C) Nota referente a una carta del capitán general de la Costa de Andalucía

El Conde Roydeville

A.G.S., Secretaría de Guerra, leg. 3.254

[en otra letra]: Respondido en 16 de abril de 1748.

Acompaña una representación que le ha hecho el cabo principal de las torres de la costa de Poniente del Puerto de Santa María, exponiendo el dańo sucedido en una de ellas, dicha del Oro, por un temporal de mar, que le ha socavado sus cimientos en extensión de más de 28 baras, hallándose por este motivo en evidente riesgo de arruinarse, y que siendo por su magnitud y artillería el refugio de las embarcaciones y la única defensa contra los moros en aquella costa, se hace preciso acudir quanto antes a su reparo. Sobre que el conde, aviendo prevenido a don Ignacio Sala nombrase un yngeniero para pasar a este reconocimiento, lo executó, advirtiéndole en la carta que incluie que, a más del expresado yngeniero, se necesita de un albañil y tres o quatro peones respecto de averse de hacer algunas catas, a fin de en su consequencia formar con conocimiento la relación del coste del reparo o proyecto si fuere menester; cuios gastos assí por lo que toca al albañil y peones, como al yngeniero, en considerarle algún socorro atento de no poder con la media paga sufragar el gasto de viages, solicitó el conde con aquel intendente providenciase a su satisfacción, y excusándose este a ello sin tener orden, lo hace presente para que se le mande lo execute. 
D) Carta del ingeniero Joseph Barnola al conde de Torre Alta.

Cádiz, 24 de octubre de 1752.

A.G.S., Secretaría de Guerra, leg. 3.258

Excelentísimo Señor.

Mui señor mío:

Satisfaciendo al asumpto de las dos cartas de Vuestra Excelencia de 7 de junio y 10 del corriente, y enterado de las copias de relaciones que haze a Vuestra Excelencia don Pedro Matheos del mal estado en que se hallan las torres de la costa de Poniente, con especialidad la del Asperillo, dispuse el reconocimiento de estas torres y costa, que executado con toda exactitud se halla que dicha torre del Asperillo está amenasando ruina de caerse desde su situación a la playa; porque estando en lo alto de un barranco de solo arena sin coagular, y penetrando las olas marítimas con los temporales siempre a más contra este barranco, está mucha parte de su fundamento descarnado, y por consiguiente irremediable con qualquier obra que se aplicase.

La torre del Río del Oro, en dos ańos consecutivos se a reparado sus fundamentos y reforzado su pie con un recalzo de cantería, y no obstante estos reparos, como se halla expuesta a los combates continuos del mar, es contingente que en lo subcessivo se destruya, como sucede en todas las obras combatidas de este elemento, que es necessario para su conservación grandes dispendios de caudales y vigilancia.

Se debe juzgar que quando se fabricaron estas torres no llegaba el mar a combatirlas y que se construirían a una prudente distancia para precaverse de su ruina; pero durante el tiempo se a hido introduciendo más y más, internándose a la tierra hasta llegar a dichas torres, dejando y aislada la del Río del Oro a 45 varas distante de la tierra, y solo en baxamar se puede comunicar con ella.

Los efectos del mar son incomprehensibles: en unas partes quita y en otras depone; pero en la costa de Poniente, inclusa la plaza de Cádiz, y de esta al Levante, observo todos los ańos que los temporales marítimos commovidos (sic) por los vientos del Sur se dirigen a internarse siempre a más a la tierra, profundando donde hallan oposición de murallas y escollos, y explayando las orillas libres de estos obstáculos. Por lo que juzgo por inútil qualquiera reparación que se aga en las citadas torres. Que es quanto susintemente devo exponer a la compreención de Vuestra Excelencia.

Dios guarde a Vuestra Excelencia muchos años como deseo. Cádiz, 24 de octubre de 1752 .

Excelentísimo Señor, beso las manos de Vuestra Excelencia. Su más atento servidor.

Don Joseph Barnola. (rúbrica)

Excelentísimo Señor Conde de la Torrealta. 
E) Carta del conde de Torre Alta al marqués de la Ensenada.

Puerto de Santa María, 12 de Diciembre de 1752.

A.G.S., Secretaría de Guerra, leg. 3.258

Excelentísimo Señor.

Mui Señor mío:

Aviéndome dado parte don Pedro Matheos, cabo de las torres de la Costa de Sanlúcar de Barramenda en la parte de Poniente, del mal estado de las nombradas El Asperillo y la del Río del Oro, y de la enminente (sic) próxima ruina que teme de la primera con los temporales, cayendo de su cituación a la playa, donde quedará inútil todo su material, lo participé al yngeniero comandante don Joseph Barnola, de que hecho cargo en su adjunta respuesta precediendo el reconocimiento que dispuso, contexta lo mismo; ańadiendo ser irremediable el daño e inútil qualquier reparo que se haga en las citadas torres, en estos términos y en el de exponer dicho don Pedro Matheos por combeniente y precisa la prompta demolición de la del Asperillo para poder aprobechar su material, que caiendo a la playa no podrá lograrse. Consultado dicho don Joseph Barnola sobre este asunto combiene en lo mismo y propone podrá encargarse esta obra a los mismos torreros, para lo que enquentro el reparo que siendo solos dos hombres, y ninguno albañil de ofizio, necesitarían de mucho tiempo para ella, sin ebitarse el riesgo de su próxima ruyna, ni el peligro de la total inutilidad de su material, caiendo al mar, que es a lo que según su estado ay que atender.

Siendo dichas torres y otras de la costa [el] único medio y el solo canal por donde se tienen las noticias de haber en ella embarcaciones de moros u otras enemigas, y también seguridad de los caminantes por las playas de la costa de Poniente, pues desde San Lucar o Cádiz hasta Ayamonte, que ay más de 20 leguas de costa, no tienen otro abrigo en aquellos mares las perseguidas de los moros que la torre del Oro principalmente, así por la conmodidad de su playa como por su grandeza y artillería, que sin ella quedarán las embarcaciones y gente que transitare en tal desamparo que en caso de algún desembarco de enemigos no habiendo en la costa quien dé el aviso podrán sin riesgo internar muchas leguas por falta de poblaciones; por lo que juzgo precisa su conserbación o construcción de otras equibalentes para poder atender al fin de la segura nabegación de aquellas embarcaciones y paso de los caminantes a que miran estas torres. Lo que pongo en noticia de Vuestra Excelencia para que sirviéndose de pasarla a la de Su Majestad se digne mandar lo que fuere de su real agrado.

Dios guarde a Vuestra Excelencia muchos años. Puerto de Santa María, 12 de diziembre de 1752.

Excelentísimo Señor, beso las manos de Vuestra Excelencia, su mayor y más afecto servidor.

El conde de la Torrealta (rúbrica)

Excelentísimo Señor Marqués de la Ensenada. 
